\title{
Hail-Induced Infections of the Chestnut Blight Pathogen Cryphonectria parasitica Depend on Wound Size and May Lead to Severe Diebacks
}

\author{
Guglielmo Lione, ${ }^{1,2}$ Luana Giordano, ${ }^{1,2}$ Massimo Turina, ${ }^{3}$ and Paolo Gonthier ${ }^{1,2, \dagger}$ \\ ${ }^{1}$ Department of Agricultural, Forest and Food Sciences (DISAFA), University of Torino, Largo Paolo Braccini 2, I-10095 Grugliasco, \\ Torino, Italy \\ ${ }^{2}$ Chestnut R\&D Center, Regione Gambarello 23, I-12013 Chiusa di Pesio, Cuneo, Italy \\ ${ }^{3}$ Institute for Sustainable Plant Protection, National Research Council of Italy (CNR), Strada delle Cacce 73, I-10135 Torino, Italy \\ Accepted for publication 24 March 2020.
}

ABSTRACT

\begin{abstract}
This study combined phytosanitary surveys, laboratory analyses, and mathematical modeling to show how hail-induced wounds can foster the infections of the blight pathogen Cryphonectria parasitica, locally associated with extensive dieback of chestnut (Castanea sativa). Orchards and coppices located within and outside the assessed dieback area in a single location in the North West of Italy were inspected to appraise the abundance of hail-induced wounds and $C$. parasitica infections. The incidence of $C$. parasitica was significantly higher within the dieback area compared with outside $(92 \%$ versus $60 \% ; P<$ $0.05)$. Hail-induced wounds were observed on small branches and shoots of all trees sampled within the dieback area, whereas they were less abundant outside ( $20 \%$ of trees), suggesting either that the dieback was directly associated with the injuries caused by the hailstorms or that those injuries may have facilitated infections of $C$. parasitica. Isolations
\end{abstract}

conducted on 359 branches and shoots showed that hail-induced wounds served as infection courts for C. parasitica and that infections depended on the size rather than on the number of hail wounds. We fitted a logistic model showing that hail-induced wounds whose perimeter was larger than $66 \mathrm{~mm}$ were at particular risk of C. parasitica infection. A newly designed geometrical-based model is proposed to relate hailstones size, hail wound perimeter, and the risk of infection. We established that hail-induced wounds are entry points for virulent and hypovirulent strains of $C$. parasitica, since $6.5 \%$ of isolates were infected by Cryphonectria hypovirus- 1 .

Keywords: analytical and theoretical plant pathology, Castanea, chestnut blight, climate change, dieback, ecology and epidemiology, epidemiology, etiology, hypovirulence, modeling, mycology, risk assessment
The European or sweet chestnut (Castanea sativa Mill.), hereafter referred to as chestnut, is a multipurpose tree species valued for timber, nuts, and for other ecosystem services (Bounous and Torello Marinoni 2005). In Southern Europe, chestnut has historically served as a key staple food and firewood source for people living in mountain areas (Conedera et al. 2004a, b). Nowadays, chestnut not only supports a niche yet important demand from the food and wood industry, but plays an important role in soil protection, landscape conservation, biodiversity conservation, and for the provision of recreational areas and the production of secondary products, including honey, tannins, and edible mushrooms (Bounous and Torello Marinoni 2005; Vogt et al. 2006).

In Europe, chestnut has been challenged by several diseases, including ink disease caused by the fungal-like organisms Phytophthora cambivora (Petri) Buisman and P. cinnamomi Rands, and chestnut blight caused by the fungus Cryphonectria parasitica (Murrill) M.E. Barr, which were responsible for severe epidemics in the 19th and 20th centuries, respectively (Gonthier and Robin 2020). More recently, chestnut has been threatened by the fungal nut rot and canker agent Gnomoniopsis castaneae G. Tamietti and by the Asian

†Corresponding author: P. Gonthier; paolo.gonthier@unito.it

Funding: This research was co-funded by the Regione Piemonte in the framework of the Project SPERECAST, by the F.E.A.S.R. 2014/2020, Project \#castagnopiemonte, and by Regione Piemonte through the activity of the Chestnut R\&D Center.

*The $e$-Xtra logo stands for "electronic extra" and indicates that five supplementary files are published online.

The author(s) declare no conflict of interest.

(C) 2020 The American Phytopathological Society gall wasp Dryocosmus kuriphilus Yasumatsu (Hymenoptera Cynipidae), an invasive insect inducing the formation of galls (Avtzis et al. 2019; Lione et al. 2019; Ôtake 1980).

Both threats first emerged in the early 2000s in the North West of Italy, and they have been subsequently reported throughout most of the distribution range of chestnut in Europe (Avtzis et al. 2019; Lione et al. 2016, 2019).

In the North West of Italy, like in many other European areas, chestnut blight has long been recognized as highly prevalent both in orchards and in coppices, although starting from the 1970s disease severity gradually decreased, especially in the oldest disease hot spots where most of the cankers were observed to heal (Gonthier and Robin 2020). The observed mitigation of chestnut blight symptoms was the result of a biological phenomenon known as hypovirulence, which is mainly due to the occurrence and spread in Europe of the virus Cryphonectria hypovirus-1 (CHV1) that is able to infect $C$. parasitica, thereby reducing its aggressiveness (Milgroom and Cortesi 2004; Rigling and Prospero 2018).

Between the late 2000s and the early 2010s, chestnut growers and forest owners reported the occurrence of severe diebacks affecting both chestnut orchards and coppices across some areas of the province of Cuneo, North West of Italy. Since the Asian gall wasp had been heavily infesting that region starting from 2001 (Quacchia et al. 2008), it was firstly argued that the pest could have been the main causal agent of the dramatic decline observed across the chestnut stands. Preliminary surveys pointed out that a prominent role in the etiology of the dieback might have been played by the blight, whose incidence and severity seemed abnormally high. However, the above surveys also led to the observation that trees had been recently challenged by intense hailstorms because of the presence of hail wounds on branches and shoots and of holes and ripping on leaves. These in-field observations were confirmed by 
reports of local farmers that claimed an increased abundance and severity of hailstorm events. It is worth noting that $C$. parasitica is a necrotrophic pathogen requiring fresh wounds or growth cracks in the bark to penetrate into the host tissues (Rigling and Prospero 2018). Therefore, hail wounds may have represented infection courts for the pathogen thus triggering blight-related diebacks as documented for other pathogens associated with blight and cankers, including the fungus Sphaeropsis sapinea (Fr.) Dyko \& B. Sutton on pines and the bacterium Erwinia amylovora (Burrill) Winslow, Broadhurst, Buchanan, Krumwiede, Rogers \& Smith on apple trees (Bobev and Deckers 1999; Lanthier 2011; Smith et al. 2002; Zwolinski et al. 1995). Hailstorms have been previously suggested to enhance the occurrence of $C$. parasitica infections (EFSA PLH Panel (EFSA Panel on Plant Health) 2014; Turchetti et al. 2010), but there is a complete lack of data and of quantitative information about the association between hail wounds on trees, the infection process, and the development of blight and cankers.

Therefore, the goals of this study were to (i) assess whether infection by $C$. parasitica may depend on the number, shape or size of hail wounds, and dimension of hailstones, and to model the risk of infection accordingly, and (ii) determine if infection through hail wounds may occur indistinctively by virus-free and virus-infected strains of the pathogen.

\section{MATERIALS AND METHODS}

Study area and sites. Diebacks of chestnuts were reported by local authorities from the second half of 2000s in the Province of Cuneo, Piedmont Region, North West of Italy, and in particular in the municipality of Peveragno (latitude $44^{\circ} 19^{\prime} 44.6^{\prime \prime}$; longitude $7^{\circ} 37^{\prime} 2.8^{\prime \prime}$; elevation $588 \mathrm{~m}$ above sea level [a.s.1.]). Preliminary surveys in the area were performed in June 2012. Diebacks involved both chestnut orchards and coppices growing on hills located WSW from the town of Peveragno and covering an approximate surface of 612 ha distributed from 600 to $1,000 \mathrm{~m}$ a.s.l. Based on their hillslope position (Miller and Schaetzl 2015), orchards were mostly located in the toeslope and lower footslope portions, while coppices covered the higher footslope, backslope, and shoulder of the hill. Trees in orchards were characterized by a mean diameter at breast height $(\mathrm{DBH})$ of approximately $53 \mathrm{~cm}$, while the $\mathrm{DBH}$ of stems in coppices ranged from 25 to $35 \mathrm{~cm}$ depending on the rotation time. Soils in the area are classified as Typic Hapludalf (IPLA-Regione Piemonte 2007). The mean annual temperature (years 1988 to 2012 ) is $10.9^{\circ} \mathrm{C}$ and the mean precipitation is 1,048 mm (ARPA-Piemonte 2019).

One peculiar feature of the dieback phenomenon was that a relatively sharp separation occurred between the dieback and the surrounding area (Figs. 1 and 2), which were similar in terms of tree species composition and stand structure. Hence, five study sites within the dieback area (w sites) and three study sites outside the dieback area (o sites) were selected across the hills surrounding the town of Peveragno (Fig. 2). The distance between w sites ranged from 544 to $1,954 \mathrm{~m}$, with an average of $1,157 \mathrm{~m}$, while o sites were separated by a distance ranging from 1,109 to 2,391 m, with an average of $1,860 \mathrm{~m}$. Each study site was established to cover a surface of about 1.5 ha encompassing both orchard and coppice.

Field inspections and samplings. A first survey was conducted on 5 June 2012 across the eight study sites. Crown transparency was estimated as a proxy of the degree of tree decline associated with diebacks, since this parameter is related to tree vitality, as documented for chestnut (Gehring et al. 2018), as well as for other tree species (Giordano et al. 2009; Jung et al. 2000; Lione et al. 2012). Crown transparency is expressed for each tree as a score appraising the leaves loss (in \%) in relation to an ideal status where defoliation is absent (Müller and Stierlin 1990). In each study site, the crowns of 15 chestnuts located along a linear transect were visually inspected and scores were assigned with the aid of a set of reference plates depicting different levels of transparency (Lione et al. 2012; Müller and Stierlin 1990), as reported below. Two viewpoints per tree were established in positions allowing a complete overview of the crown, along perpendicular compass directions and at a distance equal to the height of the tree (Durrant et al. 2006; Müller and Stierlin 1990). Crown transparency scores ranging from 0 to $100 \%$, with $5 \%$ unit increments, were assigned

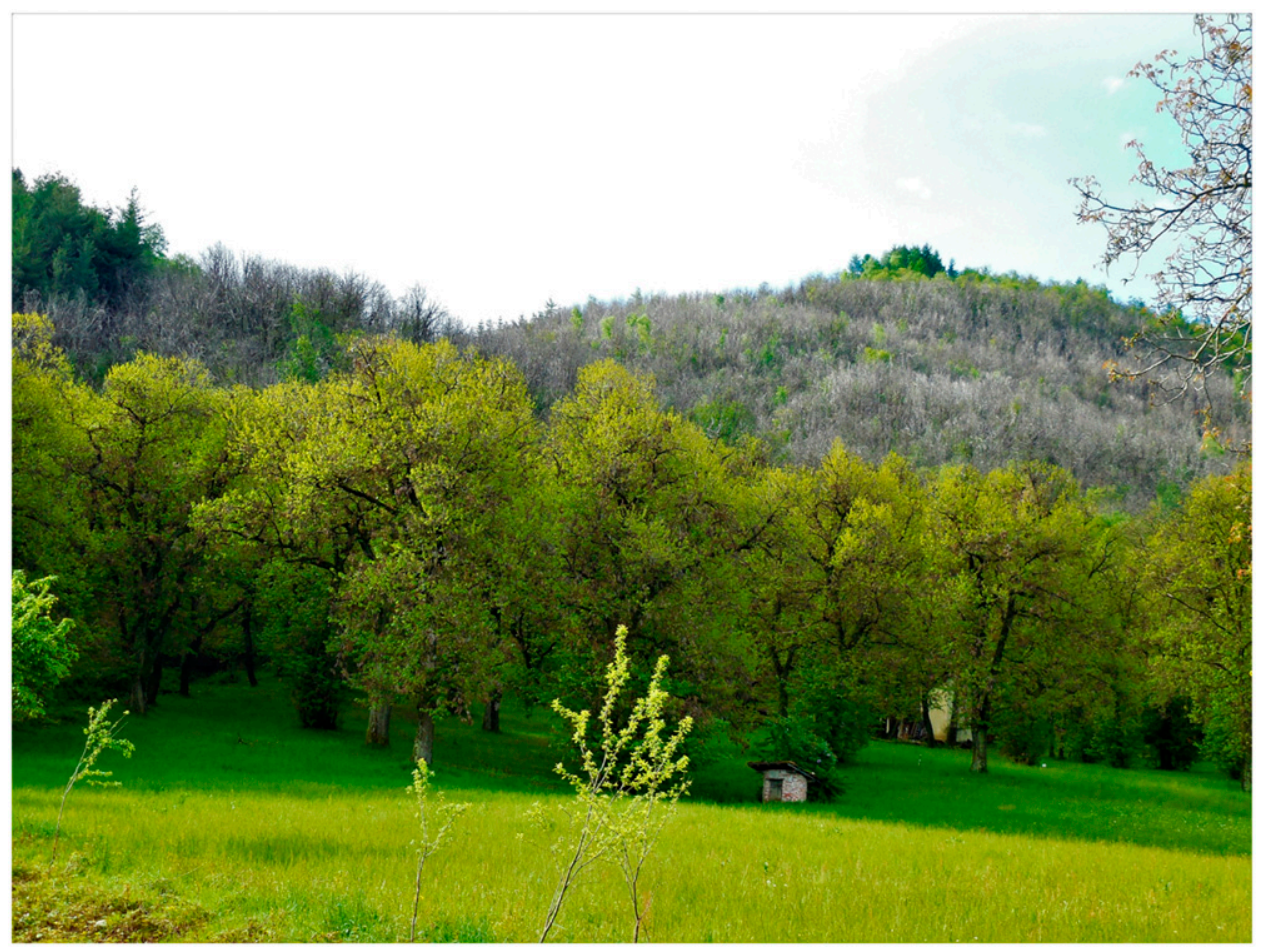

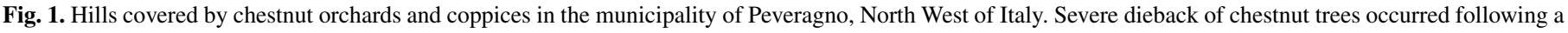
patchy spatial pattern, with a rather sharp separation between areas showing dieback symptoms and the surrounding areas. 
(Lione et al. 2012). As recommended in Durrant et al. (2006), two experienced operators performed and discussed the outcomes of the assessment and a consensus was reached.

The presence/absence of blight symptoms, galls of D. kuriphilus and hail-induced wounds was checked at the tree level as described below. In the field, up to four branches per tree were randomly selected and their terminal portion of approximately $1.50 \mathrm{~m}$ was excised and visually inspected. If at least one of these terminal portions displayed symptoms or signs of blight, galls, or hail wounds, the corresponding tree was classified as positive to the disease, the pest, or the damage, respectively. The distinction between galls and hail-induced wounds was performed visually, based on their clearly distinguishable morphology (Supplementary File S1).

Since high levels of crown transparency and the concomitant presence of both galls of $D$. kuriphilus and hail-induced wounds were observed only in sites located within the dieback area, while hail-induced wounds were significantly less abundant outside the dieback area (see results), samplings aimed at further contrasting factors potentially inciting diebacks were conducted exclusively in dieback sites during a second survey carried out on 12 November 2012. Branches and shoots of chestnut were randomly collected along linear transects established across these study sites. The experiment was initially designed to include 400 branches and shoots with an approximate length of $1.5 \mathrm{~m}, 200$ with blight symptoms and 200 without blight symptoms (i.e., asymptomatic). However, given the high abundance of blight symptoms in the area (see results), symptomatic branches and shoots were slightly oversampled, while asymptomatic branches and shoots were less abundant than expected. Hence, the final sample included 212 branches and shoots with blight symptoms and 147 asymptomatic branches and shoots. All 359 branches and shoots were taken to the laboratory for further analyses.

For both samplings, the distinction between symptomatic and asymptomatic branches and shoots was visually performed based on the presence, or not, of at least one among the typical chestnut blight symptoms described in Prospero and Rigling (2013). Galls of D. kuriphilus were detected as reported in Lione et al. (2016), while hail wounds were identified based on Costello (2014) and Schubert (1991).

Laboratory observations, isolations, and molecular analyses. The following variables were assessed in the laboratory for all 359 chestnut branches and shoots: diameter $(\mathrm{mm})$ in close proximity of the cutting surface, length $(\mathrm{cm})$, number of galls of D. kuriphilus, and number of hail wounds. For each hail wound, its length $(\mathrm{mm})$ and width $(\mathrm{mm})$ were measured and its association or not with visible blight symptoms was recorded by examining the wound surface and contour at the dissecting microscope $(40 \times$ magnification). Depending on the extension of the length to measure, either a measuring tape graduated in $\mathrm{mm}$ or a caliper were used. To confirm that symptoms observed on branches or shoots were indeed caused by $C$. parasitica, in vitro isolations were performed from one randomly selected symptomatic hail wound from $60 \%$ of symptomatic branches and shoots (127 out of 212). Five subcortical wood samples $(3 \times 2 \mathrm{~mm})$ were removed from cankers, surface disinfected using $2 \%$ sodium hypochlorite for $5 \mathrm{~min}$, and rinsed in sterile water. Subsequently, they were placed in 90-mm Petri plates containing potato dextrose agar (PDA, $39 \mathrm{~g} /$ liter) amended with citric acid ( $0.5 \mathrm{~g} /$ liter $)$. One $C$. parasitica isolate per canker was randomly selected for further analyses. Attempts of isolation were also conducted from $60 \%$ of asymptomatic branches and shoots ( 85 out of 147), by plating randomly collected pieces of wood $(3 \times 2 \mathrm{~mm})$ as previously described. Pathogen identification was performed based on macro- and micromorphological features of colonies and fruiting structures (EPPO 2005).

To determine if infection through hail wounds had occurred by either virus-free or virus-infected strains of the pathogen, both morphological and molecular diagnostic criteria were used. All $C$. parasitica isolates were grouped in the following three morphological classes: (i) virulent, cream-colored mycelium with abundant orange pycnidia, often scattered within concentric rings (orange culture morphology); (ii) hypovirulent, white mycelium and few, large pycnidia (white culture morphology); and (iii) intermediate, whitish-cream mycelium with pycnidia distributed over the entire colony (intermediate culture morphology) (Bonifacio and Turchetti 1973; Grente and Sauret 1969; Turchetti 1978). Subsequently, all isolates were tested for the presence of CHV-1 by a newly developed TaqMan-based real-time PCR assay.

A liquid culture for each isolate was prepared by transferring four to six plugs of mycelium from an actively growing solid medium culture in 250-ml flasks containing $100 \mathrm{ml}$ of Difco potato dextrose broth (PDB, Difco, U.S.A.). Flasks were incubated for 4 days at room temperature. At the end of the growing period, the medium was removed and the mycelium lyophilized for $24 \mathrm{~h}$. Total RNA was extracted from approximately $100 \mathrm{mg}$ of mycelial powder through the Spectrum Plant Total RNA Kit

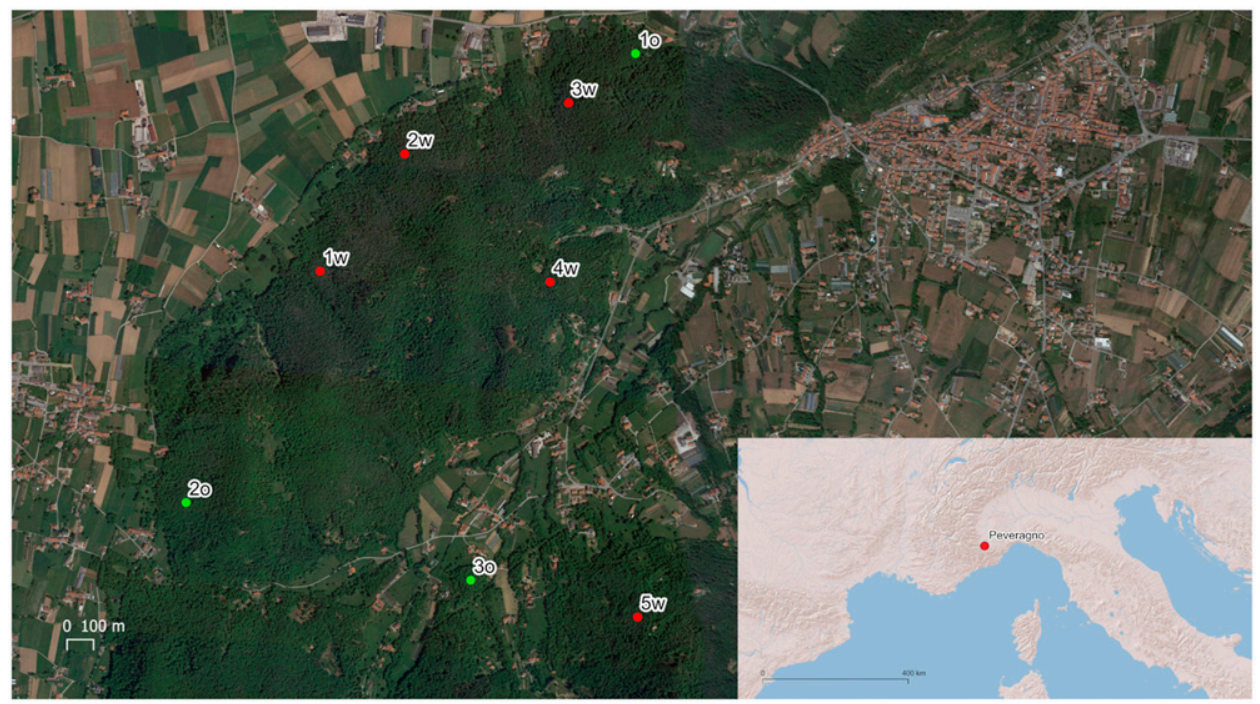

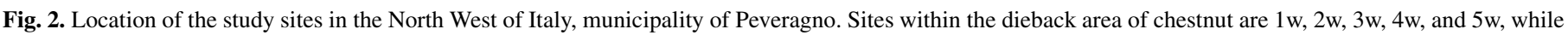

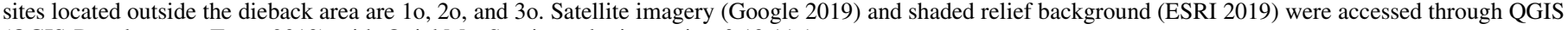
(QGIS Development Team 2019) with QuickMapServices plugin version 0.19.11.1. 
(Sigma-Aldrich, U.S.A.) following manufacturer's instructions. Complementary DNA (cDNA) was synthesized from total RNA with the High-Capacity cDNA Reverse Transcription Kit (Applied Biosystems, U.S.A.) following manufacturer's instructions. Subsequently, the TaqMan-based real-time PCR assay was performed by using four primers, CPTub-RealF/CPTub-RealRev for $C$. parasitica $\beta$-tubulin gene and CHV1-REalF/CHV1-RealRev for $\mathrm{CHV}-1$, and two TaqMan probes (Table 1). The real-time cycling protocol consisted of $95^{\circ} \mathrm{C}$ activation step for $3 \mathrm{~min}$, and 39 cycles, with each cycle consisting of $95^{\circ} \mathrm{C}$ for $10 \mathrm{~min}$ and $60^{\circ} \mathrm{C}$ for $30 \mathrm{~s}$. Reactions were carried out using a CFX Connect Real-time PCR detection system (Bio-Rad, U.S.A.) equipped with FAM reading channel. The TaqMan assay was carried out in duplicate for each $C$. parasitica isolate; one reference $C$. parasitica $\mathrm{CHV}-1$-positive isolate and one $C$. parasitica $\mathrm{CHV}$-1-negative isolate were included in the assay.

Reconstruction of the occurrence of hailstorm events. The geographic area of North West of Italy where sampling sites were located is not endowed with an official monitoring system recording hailstorms and no quantitative data or measures about position, extension and frequency of the events, as well as about the size of hailstones are available (Baldi et al. 2014; Punge and Kunz 2016). Hence, the reconstruction of hailstorms was performed through event-based and nonsystematic reports (Punge and Kunz 2016) from six people including local farmers, forest owners, and technicians of agricultural entrepreneurs associations (i.e., COLDIRETTI-Cuneo). During the interview, the date of the hailstorm events and the approximate size of the hailstones were asked. When written reports of damages related to hailstorms were available, hailstones diameter was estimated based on the threshold indicated in Baldi et al. (2014) and in the ANELFA scale relating the hail size to the expected damage to vegetation, people, vehicles, structures, and infrastructures (Dessens et al. 2007). The same information was sought through a screening of local newspapers. A further investigation was carried out by querying available meteorological and climatological datasets including the European Severe Weather Database (ESWD) provided by the European Severe Storms Laboratory (ESSL) (Dotzek et al. 2009), the European Climate Assessment \& Dataset (Van Den Besselaar et al. 2015), the Storm Report Meteonetwork Dataset (Associazione ONLUS MeteoNetwork 2019), and the Meteorologic and Idrologic Database of the Regional Agency for Environmental Protection (ARPA) of Piedmont (ARPA-Piemonte 2020). The queries were conducted by extracting all available reports of severe hailstorms occurred throughout 2011 and 2012 until 12 November across the study area.

Statistical analyses and modeling. Data from the first survey were analyzed as described below. The average score of crown transparency and the incidence of trees positive to blight symptoms, galls of $D$. kuriphilus, and hail-induced wounds (calculated as the ratio between the number of positive trees and the number of sampled trees, in \%) were compared between sites located within and outside the dieback area. Comparisons were performed by fitting conditional inference tree models based on the unbiased recursive partitioning algorithm described in Hothorn and Zeileis (2015) and Hothorn et al. (2006). The above algorithm was run by holding its default parameters, including the Bonferroni $P$ value correction for multiple comparisons (Crawley 2013). Conditional inference tree models were fitted by setting both the site and its location either within or outside the dieback area as categorical predictors. The empirical cumulative distribution functions (ECDFs) were fitted to the crown transparency scores assigned to chestnut trees in sites within and outside the dieback area (Crawley 2013).

Data from the second survey were analyzed as follows. For modeling purposes, the shape of hail-induced wounds on branches and shoots of chestnut was approximated by an ellipse (Costello 2014; Schubert 1991) with major and minor axes coincident with the length $(\mathrm{L}$, in $\mathrm{mm})$ and width $(\mathrm{W}$, in $\mathrm{mm})$ measured in the laboratory. Hence, the hail wound surface $\left(\mathrm{S}\right.$, in $\mathrm{mm}^{2}$ ) was calculated with the standard equation (equation 1), while the perimeter ( $\mathrm{p}$, in $\mathrm{mm}$ ) was approximated by using the Ramanujan's equation (equation 2) reported in Villarino (2006). To account for shape variations, ellipse eccentricity (e) was calculated with the classical equation (equation 3 ) in order to discriminate between circular $(\mathrm{e}=0)$ and stretched elliptical hail wounds $(\mathrm{e} \rightarrow 1)$.

$$
\begin{gathered}
\mathrm{S}=\frac{\pi}{4} \mathrm{LW} \\
\mathrm{p}=\pi\left[\frac{\mathrm{L}}{2}+\frac{\mathrm{W}}{2}+\frac{3\left(\frac{\mathrm{L}}{2}-\frac{\mathrm{W}}{2}\right)^{2}}{10\left(\frac{\mathrm{L}}{2}+\frac{\mathrm{W}}{2}\right)+\sqrt{\left(\frac{\mathrm{L}}{2}\right)^{2}+\frac{7}{2} \mathrm{LW}+\left(\frac{\mathrm{W}}{2}\right)^{2}}}\right] \\
\mathrm{e}=\frac{\sqrt{\left(\frac{\mathrm{L}}{2}\right)^{2}-\left(\frac{\mathrm{W}}{2}\right)^{2}}}{\frac{\mathrm{L}}{2}}
\end{gathered}
$$

By using the same conditional inference tree models described above, symptomatic and asymptomatic branches and shoots were contrasted to compare their average number of hail wounds and galls. In order to prevent any potential bias, contrasts were performed not only on hail wounds (HWC) and galls counts (GC), but also on their ratio to the length of branch or shoot (i.e., HWCL hail wounds/cm and GCL galls/cm). The average values of the variables related to wound shape and dimension (i.e., L, W, S, p, and e) were compared between symptomatic and asymptomatic branches and shoots, and between hail wounds associated with blight symptoms or not. The latter comparison was performed both on all wounds and on the subset of wounds present exclusively on symptomatic branches and shoots. In addition, ECDFs were fitted to the number of hail wounds, to the average values of $\mathrm{L}, \mathrm{W}, \mathrm{S}, \mathrm{p}$, and e of hail wounds and to the number of galls of 212 symptomatic and 147 asymptomatic branches and shoots, whose histograms were derived as well (Crawley 2013).

Based on the results of the previous analyses, binary logistic regressions (Hosmer and Lemeshow 1989) were fitted to model the probability of infection by $C$. parasitica through hail-induced wounds depending on their shape and dimension. The response variable was coded as 1 or 0 for each hail wound associated or not with blight symptoms. The corresponding values of $\mathrm{L}, \mathrm{W}, \mathrm{p}, \mathrm{S}$, and e were used as single predictors to fit binary logistic regression models $\mathrm{M}_{\mathrm{L}}, \mathrm{M}_{\mathrm{W}}, \mathrm{M}_{\mathrm{p}}, \mathrm{M}_{\mathrm{S}}$, and $\mathrm{M}_{\mathrm{e}}$, respectively, on the data gathered from 12,228 hail wounds (see results). Models' $\beta$ and $\beta_{0}$ coefficients were calculated along with their related Wald's test $P$ value (Crawley 2013; Hosmer and Lemeshow 1989). $\mathrm{M}_{\mathrm{L}}, \mathrm{M}_{\mathrm{W}}, \mathrm{M}_{\mathrm{p}}$, $\mathrm{M}_{\mathrm{S}}$, and $\mathrm{M}_{\mathrm{e}}$ were compared with the null-model $\mathrm{M}_{0}$ by testing their overall significance with the likelihood ratio test (Crawley 2013; Hosmer and Lemeshow 1989) and by contrasting the associated Akaike information criterion (AIC) and AIC weight (AICw) (Grueber et al. 2011; Wagenmakers and Farrell 2004). The 95\% confidence intervals of the probability of infection by $C$. parasitica predicted by the above binary logistic regression models were calculated with the algorithm proposed by Heiberger and Holland

TABLE 1. Primers and TaqMan probes used in this study

\begin{tabular}{ll}
$\begin{array}{l}\text { Primers and } \\
\text { TaqMan probes name }\end{array}$ & \multicolumn{1}{c}{ Sequence } \\
\hline CPTub-RealF & $5^{\prime}$ cgcaacggtcgctacctg 3' \\
CPTub-RealRev & $5^{\prime}$ tgcgcatctggtcctcg 3' \\
CPTub-TaqMan probe & $5^{\prime}$ [6FAM] gctctgccatcttccgtggtaaggtct[TAM] \\
CHV1-REalF & $5^{\prime}$ ACCTGGTTCGCCGAAGAAC 3' \\
CHV1-RealRev & $5^{\prime}$ gcaacctctaaggcaaccaatt 3' \\
CHV1-TaqMan probe & $5^{\prime}$ [6FAM] cagacacgttctggccegactgg[TAM] \\
\hline
\end{tabular}


(2015). The sample size adequacy for models fitting was checked by calculating the EPV index (number of events per variable) as described in Peduzzi et al. (1996). The EPV value was compared with the threshold value 10 (Peduzzi et al. 1996). The classification performance of the fitted models was assessed by calculating the area under the relative operating characteristic curve (area under the curve [AUC]) and its associated 95\% confidence intervals with the method described in Robin et al. (2011). The resulting AUC was compared with the threshold value 0.5 (Robin et al. 2011).

Based on the outcomes of the binary logistic regressions, pointing out that hail wound perimeter was the best predictor of the probability of infection by $C$. parasitica (see results), an appraisal on the association between hailstones size, hail wound perimeter and hence the risk of infection was conducted through a geometrical-based approach, hereafter referred to as geometrical approximation of hail wound model (GAHW). GAHW was aimed at modeling, in a three-dimension space, the shape and size of the wound created by the impact of a hailstone striking a shoot orthogonally to its growth axis, accounting for increasing contact forces. GAHW was designed and parametrized in order to build a graph relating the hail wound perimeter $\mathrm{Wp}(\mathrm{mm})$ as a function of the hailstone radius ( $\mathrm{R}$ in $\mathrm{mm}$ ), of the shoot radius ( $\mathrm{r}$ in $\mathrm{mm}$ ) and of the intensity of the impact. GAHW was designed by modeling the hailstone as a sphere of radius R (Field et al. 2010; Punge and Kunz 2016; Sun et al. 2015) and the shoot as a cylinder of radius $r$ (Lione et al. 2016; Ross et al. 1998). Sphere and cylinder were located within a Cartesian space with orthogonal axes $\mathrm{x}, \mathrm{y}$, and $\mathrm{z}$ and center $\mathrm{O}(0,0,0)$ (Lione et al. 2016) so that the cylinder axis (i.e., growth axis of the shoot in proximity of the wound) coincided with $\mathrm{z}$, and the sphere was centered on the point $\mathrm{C}\left(\mathrm{x}_{\mathrm{c}}, 0,0\right)$. Hence, the following set of equations was used to model the shoot (equation 4) and the hailstone (equation 5) in the space:

$$
\begin{gathered}
\mathrm{x}^{2}+\mathrm{y}^{2}=\mathrm{r} \\
\left(\mathrm{x}-\mathrm{x}_{\mathrm{c}}\right)^{2}+\mathrm{y}^{2}+\mathrm{z}^{2}=\mathrm{R}^{2}
\end{gathered}
$$

In this system, the hailstone falls along the direction of the $\mathrm{x}$ axis toward $\mathrm{O}$ striking the shoot with a first contact on point $(\mathrm{r}, 0,0)$. Based on the equations reported in Puttock and Thwaite (1969) that describe the external orthogonal contact of a sphere and a cylinder driven by opposite forces, the shape of a hail-induced wound on a shoot was modeled as the geometric intersection between the sphere and the cylinder. This geometric intersection was assumed as a proxy of the wound resulting from the physical indentation $\alpha$ (Puttock and Thwaite 1969) or $\delta_{\max }$ (Sun et al. 2015) created by the hailstone impact on the shoot. Hence, the wound perimeter was defined by the set of points belonging to both the sphere and the cylinder once the intersection had occurred. GAHW was run by setting as input variables the values of $R, r$, and $x_{c}$. The first variable can be set by the user based on the observed or expected hailstorm intensity (i.e., hailstorm average radius), the second can be set based on the size of the branches, while the third varies during the fall of the hailstone, attaining its minimum value when the wound is created and hence the maximum indentation is reached. As the physical properties of chestnut shoots to parametrize the equations reported in Puttock and Thwaite (1969) and Sun et al. (2015) were not available in the literature, $\alpha$ (and hence $\mathrm{x}_{\mathrm{c}}$ ) could not be set directly. Therefore, since the indentation is directly proportional (i.e., $\propto$ ) to the radius of the hailstone $[\alpha \propto\|\overrightarrow{\mathrm{P}}\|$, see Puttock and Thwaite (1969), where $\|\overrightarrow{\mathrm{P}}\|=\left\|\overrightarrow{F_{c}}\right\| \propto v \propto D_{\text {hail }}$, see equations 1, 18, and A2 in Sun et al. (2015)] and it can be expressed either in the same unit of measurement of R, or as fraction of R (Puttock and Thwaite 1969), hailstone impact on the shoot was assumed to reach the maximum depth of $\mathrm{R} / \mathrm{n}$. $\mathrm{R}$ and $\mathrm{n}$ values were consequently selected based on (i) the visual observation aimed at appraising the approximate depth of hail wounds present on the sampled shoots, and (ii) the expected range of hailstone radius according to the reconstruction of recent hailstorm events (see results) and to the climatologies available for the North West of Italy (Baldi et al. 2014; Punge and Kunz 2016). The range of $r$ values was set based on the sizes of chestnut shoots comparable with those sampled in this study. Once the values of $\mathrm{R}, \mathrm{r}$, and $\mathrm{n}$ had been fixed for each hailstone impact, the coordinates $\mathrm{x}_{\mathrm{Wp}}, \mathrm{y}_{\mathrm{Wp}}$, and $\mathrm{z}_{\mathrm{Wp}}$ of points lying on the spatial curve at the intersection of the sphere and the cylinder were calculated using equation 6 by setting discrete steps of $10^{-5}$ radians for $\theta$ :

$$
\left\{\begin{array}{c}
\mathrm{x}_{\mathrm{c}}=\frac{\mathrm{n}-1}{\mathrm{n}} \mathrm{R}+\mathrm{r} \\
b=\frac{\mathrm{R}^{2}-\mathrm{r}^{2}-\mathrm{x}_{\mathrm{c}}^{2}}{2 \mathrm{x}_{\mathrm{c}}} \\
\theta_{0}=\arccos \left(-\frac{\mathrm{b}}{\mathrm{r}}\right) \\
-\theta_{0}<\theta<\theta_{0} \\
\mathrm{x}_{\mathrm{Wp}}=\mathrm{r} \cdot \cos \theta \\
\mathrm{y}_{\mathrm{Wp}}=\mathrm{r} \cdot \sin \theta \\
\mathrm{z}_{\mathrm{Wp}}= \pm \sqrt{2 \mathrm{x}_{\mathrm{c}}(\mathrm{b}+\mathrm{r} \cdot \cos \theta)}
\end{array}\right.
$$

The calculation of the perimeter of each simulated hail wound on the shoot was approximated by summing the Euclidean distances between all consecutive points lying on the curve at the intersection of the sphere and the cylinder (Dobrow 2016). GAHW was run on all possible combinations of three representative values of $n$ and $r$, plotting for any combination the graph displaying the relation between $\mathrm{Wp}$ and $\mathrm{R}$.

The risk of blight insurgence at shoot level was obtained by integrating the GAHW model with the binary logistic regression modeling the probability of infection $(\%)$ by $C$. parasitica as a function of the hail wound perimeter.

For all analyses the $95 \%$ bias corrected and accelerated confidence interval (CI) was calculated for the averages based on $10^{4}$ bootstrap resamplings (Carpenter and Bithell 2000; Carsey and Harden 2014; DiCiccio and Efron 1996). For proportions (e.g., incidences), exact $95 \%$ confidence intervals were calculated as reported in Blaker (2000). Both types of confidence intervals are abbreviated with the acronym CI throughout the text. Statistical analyses and modeling were conducted with $\mathrm{R}$ version 3.6.0 ( $\mathrm{R}$ Core Team 2019) and with the associated packages bootstrap (Efron and Tibshirani 1994), HH (Heiberger and Holland 2015), MuMIn (Barton 2019), partykit (Hothorn and Zeileis 2015), pROC (Robin et al. 2011), rgl (Adler and Murdoch 2019), and strucchange (Zeileis et al. 2002). The significance threshold was set to 0.05 for all tests.

\section{RESULTS}

Assessing factors associated with dieback of chestnut trees. Results from the conditional inference tree models pointed out that the average score of crown transparency was significantly higher within the dieback area $(53.7 \%, 50.4$ to $57.0 \%$ confidence interval) than outside $(20.1 \%, 17.1$ to $23.1 \% \mathrm{CI})(P<0.001)$ (Table 2). The ECDFs of crown transparency scores assessed within and outside the dieback areas are shown in Supplementary File S2. Based on the outcomes of conditional inference tree models, the incidence of symptoms of chestnut blight was significantly higher within $(92.0 \%, 83.7$ to $96.5 \% \mathrm{CI})$ than outside $(60.0 \%, 44.5$ to $73.8 \% \mathrm{CI})$ the dieback area $(P<0.001)$ (Table 2$)$. Conversely, the 
frequency of trees positive to the presence of $D$. kuriphilus galls was comparable and not significantly different $(P=0.824)$ within $(88.0 \%, 79.0$ to $93.8 \% \mathrm{CI})$ and outside the dieback area $(84.4 \%$, 71.4 to $92.9 \% \mathrm{CI}$ ), since the corresponding conditional inference tree models did not display any significant split. Hail-induced wounds on branches and shoots were present on $100 \%$ (95.2 to $100 \% \mathrm{CI}$ ) of the inspected trees in the dieback area, while they were significantly less prevalent $(20.0 \%, 10.5$ to $34.1 \% \mathrm{CI})$ outside the dieback area $(P<0.001)$, as confirmed by the presence of two terminal nodes in the corresponding conditional inference tree model (Table 2). In summary, for all the above mentioned comparisons, splits of conditional inference tree models occurred only in the comparison between sites within and outside the dieback area (Table 2). Hence, the levels of infestation of the Asian gall wasp were similar within and outside the dieback area, whereas the incidence of chestnut blight was significantly higher, in association with average levels of crown transparency exceeding $50 \%$, in the dieback area compared with the surrounding stands.

Pathogen isolation and characterization of the hypovirulence. Isolations allowed to confirm the association between the presence of symptoms of blight on hail-induced wounds and the presence of C. parasitica. In fact, 124 isolates of $C$. parasitica were obtained from symptomatic branches and shoots (isolation frequency $97.6 \%$ ). No isolates of the pathogen were obtained from asymptomatic samples (isolation frequency 0\%). Of the 124 isolates, 38 (30.6\%) had a virulent, orange culture morphology, whereas 84 $(67.7 \%)$ were characterized as intermediate. Only two isolates $(1.6 \%)$ had a hypovirulent, white culture morphology. The TaqMan-based real-time PCR assay confirmed the occurrence of CHV-1 in the white isolates as well as in six additional isolates classified as intermediate. All remaining isolates $(93.5 \%)$ were virus-free.

Assessment of the relation between infection by $\boldsymbol{C}$. parasitica and the number or size of hail wounds. The 359 branches and shoots collected during the second sampling had an average diameter of $9.9 \mathrm{~mm}(9.4$ to $10.3 \mathrm{~mm} \mathrm{CI})$ and a mean length of $144.5 \mathrm{~cm}$ (137.7 to $151.9 \mathrm{~cm} \mathrm{CI})$. On them, a total of 12,228 hail wounds and 1,961 galls of $D$. kuriphilus were detected, corresponding to an average of 0.25 hail wounds/cm ( 0.23 to 0.26 hail wounds/ $\mathrm{cm} \mathrm{CI})$ and 0.036 galls $/ \mathrm{cm}(0.033$ to 0.041 galls/cm CI). On average, a single hail wound measured $7.50 \mathrm{~mm}(7.40$ to $7.61 \mathrm{~mm} \mathrm{CI})$ in length and $2.70 \mathrm{~mm}$ (2.66 to $2.73 \mathrm{~mm} \mathrm{CI})$ in width, with a perimeter of $17.1 \mathrm{~mm}$ (16.9 to $17.3 \mathrm{~mm} \mathrm{CI})$, a surface of $21.6 \mathrm{~mm}^{2}$ (21.0 to $\left.22.3 \mathrm{~mm}^{2} \mathrm{CI}\right)$ and an eccentricity of 0.846 (0.842 to $\left.0.850 \mathrm{CI}\right)$. On the whole, hail wounds associated with blight symptoms were 3,285 out of $12,228(26.9 \%)$. However, they accounted for $50.4 \%$ of the total number of hail wounds observed on the symptomatic branches and shoots, while no hail wounds were associated with blight in asymptomatic branches.

By contrasting the 212 symptomatic and 147 asymptomatic branches and shoots, a significant split of the conditional inference tree model showed that the first displayed an average number of hail wounds significantly lower than the latter (30.7 versus $38.9, P=$ $\left.2.701 \times 10^{-3}\right)$. Nonetheless, in the 212 symptomatic branches and shoots the average values of the shape and dimension variables of hail wounds L, W, S, p, and e were higher than those from the 147 asymptomatic samples, although not always significantly depending on the number of terminal nodes of the corresponding conditional inference tree models (Table 3). Galls abundance was significantly lower in asymptomatic than in symptomatic branches and shoots (4.34 versus 7.08, $P<0.001$ ), separated in two terminal nodes of the related conditional inference tree model. The ECDFs fitted to the number, average $\mathrm{L}, \mathrm{W}, \mathrm{S}, \mathrm{p}$, and e of hail wounds and to the number of galls of 212 symptomatic and 147 asymptomatic branches and shoots are shown in Supplementary File S3 along with the related histograms.

Results obtained for hail wounds and galls abundance were confirmed by their corresponding counterparts related to the length of the branches and shoots HWCL and GCL, respectively (Table 3).

Comparisons of size variables showed that on average hail wounds associated with blight symptoms were significantly $(P<$ $0.05)$ larger than the others, with the associated conditional inference tree models displaying two terminal nodes (Table 4). On the total sample of branches and shoots, hail wounds colonized by $C$. parasitica significantly $(P<0.05)$ exceeded the dimensions of the other wounds by $24.7 \%$ for the length L, $15.8 \%$ for the width W, $45.8 \%$ for the surface $\mathrm{S}$, and $23.6 \%$ for the perimeter $\mathrm{p}$, as shown by the presence of significant splits in the related conditional inference trees (Table 4). Similar results were obtained from the splits displayed by the models fitted on the subset of symptomatic branches and shoots, where hail wounds associated with the pathogen significantly $(P<0.05)$ exceeded the wounds not associated with blight by $25.8 \%$ for $\mathrm{L}, 11.1 \%$ for $\mathrm{W}, 39.3 \%$ for $\mathrm{S}$, and $23.6 \%$ for $\mathrm{p}$. Moreover, the shape variable expressing the eccentricity of the hail wounds was significantly $(P<0.05)$ different in both cases, showing that wounds infected by $C$. parasitica were more stretched than those not colonized by the pathogen, since their e value was higher in both comparisons performed (Table 4).

Modeling the risk of infection of $C$. parasitica based on hail wounds shape and size. The binary logistic regression models pointed out that all tested shape and dimensions predictors were positively $(\beta>0)$ and significantly $(P<0.05)$ associated with the probability of infection by $C$. parasitica through hail-induced wounds (Table 5). For all models the likelihood ratio test confirmed that increasing length, width, perimeter, surface and eccentricity of the hail wound significantly $(P<0.05)$ increase the risk of blight insurgence, although some of the above predictors outperformed the others in terms of model performances. In fact, based on the minimum AIC principle, $\mathrm{M}_{\mathrm{p}}$ was the best scoring model, followed by $\mathrm{M}_{\mathrm{L}}, \mathrm{M}_{\mathrm{S}}, \mathrm{M}_{\mathrm{W}}$, and $\mathrm{M}_{\mathrm{e}}$ (Table 5). Based on AICw values, $\mathrm{M}_{\mathrm{p}}$ is the most adequate model to describe the risk of infection with a

TABLE 2. Mean crown transparency (MCT) values and incidence of chestnut blight symptoms (ICBS), of Dryocosmus kuriphilus galls (IDK), and of hail-induced wounds (IHIW) in the study sites located within and outside the dieback area ${ }^{\mathrm{z}}$

\begin{tabular}{|c|c|c|c|c|c|c|c|c|c|}
\hline Study site & MCT & ICBS & IDK & IHIW & $\begin{array}{l}\text { Study site } \\
\text { location }\end{array}$ & MCT & ICBS & IDK & IHIW \\
\hline 10 & $19.3(14.3-25.3) b$ & $73.3(46.5-90.3) b$ & $73.3(46.5-90.3) \mathrm{a}$ & $13.3(2.4-39.4) \mathrm{b}$ & \multirow{3}{*}{$\begin{array}{c}\text { Outside the } \\
\text { dieback } \\
\text { area }\end{array}$} & \multirow[t]{3}{*}{$20.1(17.1-23.1) b$} & \multirow[t]{3}{*}{$60.0(44.5-73.8) b$} & \multirow[t]{3}{*}{$84.4(71.4-92.9) \mathrm{a}$} & \multirow[t]{3}{*}{$20.0(10.5-34.1) b$} \\
\hline 20 & $23.3(18.0-28.3) b$ & $46.7(21.5-71.0) \mathrm{b}$ & $86.7(60.6-97.6) \mathrm{a}$ & $20.0(5.7-46.5) b$ & & & & & \\
\hline 30 & $17.7(13.3-22.0) \mathrm{b}$ & $60.0(33.2-81.3) b$ & $93.3(69.8-99.7) \mathrm{a}$ & $26.7(9.7-53.5) \mathrm{b}$ & & & & & \\
\hline $1 \mathrm{w}$ & $53.7(47.7-58.3) \mathrm{a}$ & $100(78.5-100) \mathrm{a}$ & $86.7(60.6-97.6) \mathrm{a}$ & $100(78.5-100) \mathrm{a}$ & \multirow{5}{*}{$\begin{array}{c}\text { Within the } \\
\text { dieback } \\
\text { area }\end{array}$} & \multirow[t]{5}{*}{$53.7(50.4-57.0) \mathrm{a}$} & \multirow[t]{5}{*}{$92.0(83.7-96.5) \mathrm{a}$} & \multirow[t]{5}{*}{$88.0(79.0-93.8) \mathrm{a}$} & \multirow[t]{5}{*}{$100(95.2-100) \mathrm{a}$} \\
\hline $2 \mathrm{w}$ & $50.3(41.7-58.3) \mathrm{a}$ & $86.7(60.6-97.6) \mathrm{a}$ & $86.7(60.6-97.6) \mathrm{a}$ & $100(78.5-100) \mathrm{a}$ & & & & & \\
\hline $3 w$ & $56.7(50.3-62.0) \mathrm{a}$ & 93.3 (69.8-99.7) a & $93.3(69.8-99.7) \mathrm{a}$ & $100(78.5-100) \mathrm{a}$ & & & & & \\
\hline $4 w$ & $59.3(52.0-66.6) \mathrm{a}$ & $93.3(69.8-99.7) \mathrm{a}$ & 86.7 (60.6-97.6) a & $100(78.5-100) \mathrm{a}$ & & & & & \\
\hline $5 w$ & $48.7(41.0-57.3) \mathrm{a}$ & $86.7(60.6-97.6) \mathrm{a}$ & $86.7(60.6-97.6) \mathrm{a}$ & $100(78.5-100) \mathrm{a}$ & & & & & \\
\hline
\end{tabular}

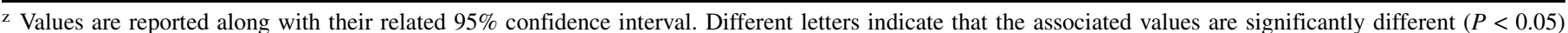
since they are split in two different terminal nodes by the conditional inference tree model. Conversely, the same letter indicates values not significantly different $(P>0.05)$ that are included within the same node of the conditional inference tree model. Comparisons conducted with such models are reported by columns in the table. 
probability of $97.9 \%$, while $\mathrm{M}_{\mathrm{L}}$ attained a probability of $2.1 \%$ and the others did not exceed the threshold of $0 \%$ (Table 5). $\mathrm{M}_{\mathrm{p}}$ sigmoid curve (Fig. 3) shows that wounds perimeter below the threshold of $66 \mathrm{~mm}$ are associated with a probability of infection lower than $50 \%$ ( 46 to $53 \% \mathrm{CI}$ ), while for those with a perimeter of $107 \mathrm{~mm}$ the risk increases up to a probability of $70 \%$ (64 to $75 \%$ CI), which further grows over $90 \%$ ( 86 to $94 \%$ CI) for perimeters exceeding the $172 \mathrm{~mm} . \mathrm{M}_{\mathrm{p}}$ curve is shown in logit scale in Supplementary File S4. Most of the perimeter values used for fitting model $M_{p}$ ranged from 0 to $100 \mathrm{~mm}$, while values over $100 \mathrm{~mm}$ represented less than $1 \%$ of the sample size (Fig. 3). The EPV index attained the value of 3285 , which was largely over the threshold of 10 . The AUC value of model $\mathrm{M}_{\mathrm{p}}$ was 0.59 with an associated $95 \% \mathrm{CI}$ ranging from 0.58 to 0.60 , hence significantly over the 0.5 threshold.

Reconstruction of the hailstorm events. The interviews of the local farmers, forest owners and technicians of agricultural entrepreneurs association revealed that at least three intense hailstorms impacted the dieback area during 2012, the first occurring on 10 May, the second on 18 June, and the third on 22 August. Based on the descriptions provided during the interviews, hailstones size was "larger than a hazelnut" or "as big as a walnut", hence it was estimated that the average diameter of the hail could be in the range 1 to $3 \mathrm{~cm}$ according to the indications reported in Baldi et al. (2014) and in the ANELFA scale (Dessens et al. 2007). Based on reports of hailstorm damage addressed to the municipality of Peveragno (S. Marchisio, COLDIRETTI-Cuneo, personal communication) the event of June was probably the most intense, with a diameter of hailstones of about $3 \mathrm{~cm}$, as confirmed by local newspapers (Prieri 2012) and by the ANELFA scale (Dessens et al. 2007). For the year 2011, at least one intense event was reported by half of the interviewed people, although there was no agreement on the exact timeframe, which was set approximately in the first half of November. Based on information reported by local online newspapers, the event could have taken place in association with the heavy rains and floods of 6 November (Cariddi 2011). The queries

TABLE 3. Comparison of hail wounds number, shape, and size variables, and of galls abundance between symptomatic and asymptomatic branches and shoots ${ }^{\mathrm{z}}$

\begin{tabular}{|c|c|c|c|}
\hline Variable & Symptomatic branches and shoots & Asymptomatic branches and shoots & $P$ value \\
\hline HWC* & $30.7(27.7-34.1) b$ & $38.9(34.8-43.4) \mathrm{a}$ & $2.701 \times 10^{-3}$ \\
\hline HWCL* & $0.21(0.19-0.23) \mathrm{b}$ & $0.30(0.28-0.33) \mathrm{a}$ & $<0.001$ \\
\hline $\mathrm{L}$ & $7.89(7.52-8.32) \mathrm{a}$ & $7.40(7.07-7.77) \mathrm{a}$ & $9.575 \times 10^{-2}$ \\
\hline $\mathrm{S}^{*}$ & $22.8(20.7-25.4) \mathrm{a}$ & $19.3(17.7-21.0) \mathrm{b}$ & $2.818 \times 10^{-2}$ \\
\hline $\mathrm{p}$ & $17.9(17.1-18.8) \mathrm{a}$ & $16.7(16.1-17.5)$ a & $5.998 \times 10^{-2}$ \\
\hline e & $0.863(0.851-0.873) \mathrm{a}$ & $0.846(0.828-0.861) \mathrm{a}$ & $8.849 \times 10^{-2}$ \\
\hline $\mathrm{GC}^{*}$ & $4.34(3.71-5.06) \mathrm{a}$ & $7.08(5.89-8.57) \mathrm{b}$ & $<0.001$ \\
\hline
\end{tabular}

${ }_{\mathrm{z}}$ Average values are reported along with their related 95\% confidence interval. Different letters indicate that the associated values are significantly different $(P<$ 0.05 ) since they are split in two different terminal nodes by the conditional inference tree model. Conversely, the same letter indicates values not significantly different $(P>0.05)$ that are included within the same node of the conditional inference tree model. The variables displaying significant differences are marked with asterisks. Comparisons are reported by row in the table along with the corresponding $P$ value. HWC, hail wounds count (number of wounds); HWCL, hail wounds count related to the length of the branches and shoots (number of wounds $/ \mathrm{cm}$ ); L, length of the hail wound (mm); W, width of the hail wound (mm); S, surface of the hail wound $\left(\mathrm{mm}^{2}\right)$; p, perimeter of the hail wound $(\mathrm{mm})$; and e, eccentricity of the hail wound.

TABLE 4. Comparison of shape and size variables between hail wounds associated or not associated with blight symptoms ${ }^{\mathrm{z}}$

\begin{tabular}{|c|c|c|c|c|c|c|}
\hline Variable & $\begin{array}{l}\text { Hail wounds associated } \\
\text { with blight }\end{array}$ & $\begin{array}{l}\text { Hail wounds not associated } \\
\text { with blight }\end{array}$ & $\begin{array}{c}P \\
\text { value }\end{array}$ & $\begin{array}{c}\text { Hail wounds associated with } \\
\text { blight in symptomatic branches } \\
\text { and shoots }\end{array}$ & $\begin{array}{c}\text { Hail wounds not associated with } \\
\text { blight in symptomatic branches } \\
\text { and shoots }\end{array}$ & $\begin{array}{c}P \\
\text { value }\end{array}$ \\
\hline $\mathrm{L}^{*}$ & $8.78(8.53-9.06) \mathrm{a}$ & $7.04(6.93-7.15) \mathrm{b}$ & $<0.001$ & $8.78(8.53-9.06) \mathrm{a}$ & $6.98(6.80-7.17) b$ & $<0.001$ \\
\hline $\mathrm{W}^{*}$ & $3.00(2.93-3.08) \mathrm{a}$ & $2.59(2.55-2.62) b$ & $<0.001$ & $3.00(2.93-3.08) \mathrm{a}$ & $2.70(2.64-2.77) b$ & $<0.001$ \\
\hline $\mathrm{S} *$ & $28.0(26.4-30.0) \mathrm{a}$ & 19.2 (18.6-19.9) b & $<0.001$ & $28.0(26.4-30.0) \mathrm{a}$ & $20.1(19.0-21.5) b$ & $<0.001$ \\
\hline $\mathrm{p}^{*}$ & 19.9 (19.3-20.4) a & $16.1(15.9-16.3) b$ & $<0.001$ & 19.9 (19.3-20.4) a & $16.1(15.7-16.5) \mathrm{b}$ & $<0.001$ \\
\hline $\mathrm{e}^{*}$ & $0.871(0.864-0.876) \mathrm{a}$ & $0.837(0.832-0.842) \mathrm{b}$ & $<0.001$ & $0.871(0.864-0.876)$ a & $0.856(0.849-0.862) b$ & $<0.001$ \\
\hline
\end{tabular}

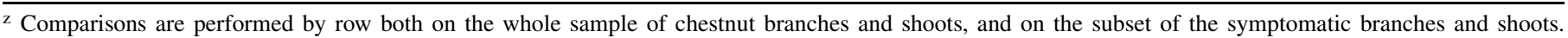
Average values are reported along with their related $95 \%$ confidence interval. Different letters indicate that the associated values are significantly different $(P<$ 0.05) since they are split in two different terminal nodes by the conditional inference tree model. The variables displaying significant differences are marked with asterisks. L, length of the hail wound $(\mathrm{mm})$; W, width of the hail wound $(\mathrm{mm}) ; \mathrm{S}$, surface of the hail wound (mm²); $\mathrm{p}$, perimeter of the hail wound (mm); and e, eccentricity of the hail wound.

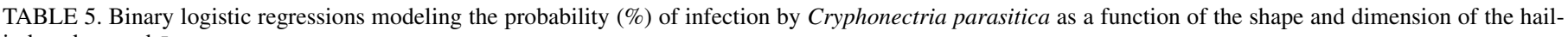
induced wounds ${ }^{\mathrm{z}}$

\begin{tabular}{|c|c|c|c|c|c|c|c|c|c|}
\hline Model & $\beta_{0}$ & $\operatorname{SE}\left(\beta_{0}\right)$ & $P\left(\beta_{0}\right)$ & $\beta$ & $\operatorname{SE}(\beta)$ & $P(\beta)$ & AIC & $\mathrm{AIC}_{\mathrm{W}}$ & $P(\mathrm{LRT})$ \\
\hline $\mathrm{M}_{0}$ & $-1.001 *$ & $2.04 \times 10^{-2}$ & $<0.001$ & - & - & - & $14,233.1$ & 0 & - \\
\hline $\mathrm{M}_{\mathrm{L}} *$ & $-1.336^{*}$ & $3.32 \times 10^{-2}$ & $<0.001$ & $4.295 \times 10^{-2 *}$ & $3.28 \times 10^{-3}$ & $<0.001$ & $14,056.6$ & 0.021 & $<0.001$ \\
\hline $\mathrm{M}_{\mathrm{W}} *$ & $-1.303^{*}$ & $3.56 \times 10^{-2}$ & $<0.001$ & $1.085 \times 10^{-1 *}$ & $1.02 \times 10^{-2}$ & $<0.001$ & $14,124.0$ & 0 & $<0.001$ \\
\hline $\mathrm{M}_{\mathrm{p}} *$ & $-1.368 *$ & $3.48 \times 10^{-2}$ & $<0.001$ & $2.070 \times 10^{-2 *}$ & $1.55 \times 10^{-3}$ & $<0.001$ & $14,048.9$ & 0.979 & $<0.001$ \\
\hline $\mathrm{M}_{\mathrm{S}} *$ & $-1.130^{*}$ & $2.41 \times 10^{-2}$ & $<0.001$ & $5.662 \times 10^{-3 *}$ & $5.50 \times 10^{-4}$ & $<0.001$ & $14,119.0$ & 0 & $<0.001$ \\
\hline $\mathrm{M}_{\mathrm{e}}^{*}$ & $-1.656^{*}$ & $9.32 \times 10^{-2}$ & $<0.001$ & $7.655 \times 10^{-1 *}$ & $1.05 \times 10^{-1}$ & $<0.001$ & $14,176.3$ & 0 & $<0.001$ \\
\hline
\end{tabular}

${ }^{z}$ Models $M_{L}, M_{W}, M_{p}, M_{S}$, and $M_{e}$ include as single predictors the length ( $L$, in mm), width (W, in mm), perimeter (p, in mm), surface ( $S$, in mm ${ }^{2}$ ), and eccentricity (e) of the hail wounds, while $\mathrm{M}_{0}$ is the null model. For the estimates of the intercept $\left(\beta_{0}\right)$ and the predictors' coefficients $(\beta)$, the associated standard errors (SE) and Wald's test $P$ value $(P)$ are reported. The Akaike information criterion (AIC), AIC weight (AIC $\left.{ }_{\mathrm{w}}\right)$, and the likelihood ratio test (LRT) $P$ value $(P$ ) are shown for each model. Asterisks next to the $\beta$ or $\beta_{0}$ values indicate significant $(P<0.05)$ Wald's tests outcomes, while asterisks next to the model label mark significant $(P<0.05)$ likelihood ratio tests. 
performed on the European Severe Weather Database and on the Storm Report Meteonetwork Dataset did not provide any hailstorm record for the study area, while the European Climate Assessment \& Dataset and the Meteorologic and Idrologic Database of the Regional Agency for Environmental Protection (ARPA) of Piedmont did not contain specific information related to hailstorm occurrence.
Appraisal of the association between hailstones size, wound dimensions and risk of infection. The application of the GAHW approach resulted in a R algorithm (Supplementary File S5) allowing for the three-dimensional modeling of the shape of hail wounds on branches (Fig. 4). The virtual rendering of the hail wounds shape was visually consistent with the observations carried out on the chestnut samples (Fig. 5) and was in agreement with the
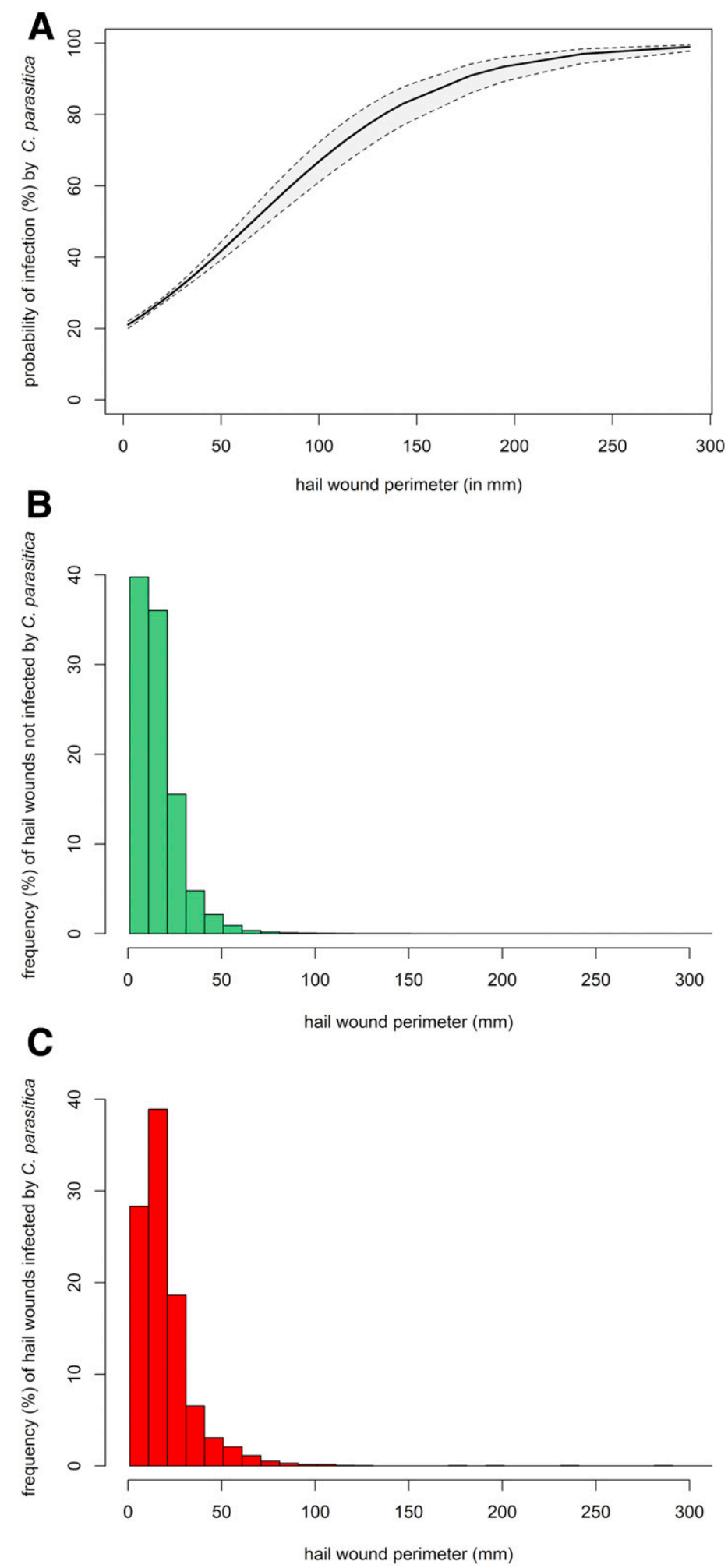

Fig. 3. A, Sigmoid curve of the binary logistic regression modeling the probability of infection (\%) by Cryphonectria parasitica as a function of the hail wound perimeter (in $\mathrm{mm}$ ). The region comprised between the contours above and below the curve delimits the $95 \%$ confidence interval of the predicted probability. B and $\mathbf{C}$, The frequency (\%) of hail wounds used for the model fitting is shown as a function of the perimeter (in mm) in histograms of wounds $\mathbf{B}$, not infected and $\mathbf{C}$, infected by $C$. parasitica. 
elliptical approximation of the wound contour proposed in Costello (2014) and Schubert (1991).

$\mathrm{R}, \mathrm{r}$, and $\mathrm{n}$ parameters that served as input for the GAHW model ranged between 1 and $25 \mathrm{~mm}$ for the hailstone radius $\mathrm{R}$, between 5 and $20 \mathrm{~mm}$ for the shoot radius $\mathrm{r}$, and between 3 and 10 for hailstorm severity parameter $\mathrm{n}$. Within the above intervals, a discrete step of $1 \mathrm{~mm}$ was set for $\mathrm{R}$, while the representative values 5,10 , and $20 \mathrm{~mm}$ were selected for $r$ and 3,5 , and 10 for $n$. The outcome of the GAHW model (Fig. 6) showed that the hail wound perimeter increased linearly from values close to $1 \mathrm{~mm}$ up to values close to $100 \mathrm{~mm}$ with increasing hailstone radius from 1 to $25 \mathrm{~mm}$. The rate of linear increase of the hail wound perimeter (i.e., slope of the linear plot) grows with decreasing values of $n$, and with increasing values of $r$ (Fig. 6). The risk of blight insurgence at shoot level can be obtained by integrating the GAHW model (Fig. 6) with the binary logistic regression modeling the probability of infection (\%) by C. parasitica as a function of the hail wound perimeter (Fig. 3). For instance, the GAHW model shows that during a severe hailstorm $(n=3)$, an increase of the hailstone radius from 5 to $25 \mathrm{~mm}$ increases the expected hail wound perimeter from 19 to $86 \mathrm{~mm}$ on a chestnut shoot of $5 \mathrm{~mm}$ radius. In this situation, the corresponding risk of infection by $C$. parasitica resulting from the binary logistic regression model increases from 27 to $60 \%$.

\section{DISCUSSION}

By combining the outcomes of surveys conducted within and outside the dieback area with laboratory analyses and mathematical modeling, we were able to link the observed dieback of chestnut orchards and coppices to an outbreak of blight in turn triggered by hailstorm events. Furthermore, we identified the size of hail wounds as an important factor increasing the risk of $C$. parasitica infection and we observed that both virus-free and virus-infected strains of the pathogen may gain access into the host tissues through hail wounds.
The dieback appeared in the same area where both the Asian gall wasp (Avtzis et al. 2019) and chestnut nut rots caused by G. castaneae (Lione et al. 2019; Visentin et al. 2012) were first reported in Europe at the beginning of the century. However, despite G. castaneae has been reported in Switzerland to cause cankers similar to those of $C$. parasitica (Pasche et al. 2016), our isolations from symptomatic tissues would exclude any role of $G$. castaneae on the onset of symptoms, which instead appear to be caused exclusively by $C$. parasitica. The latter was never isolated from asymptomatic samples, although occasionally the fungus was reported to live endophytically in shoots and in the bark of Castanea sativa (Bissegger and Sieger 1994; Chandelier et al. 2019).

To determine the role of the different factors on the onset of the dieback, we combined the assessment of crown transparency with phytosanitary surveys and analyses, with an approach similar to that employed for studying diebacks of other tree species, including pines and oaks (Giordano and Gonthier 2011; Giordano et al. 2009; Gonthier et al. 2010; Jung et al. 2000; Lione et al. 2012). Infestations of the Asian gall wasp and chestnut blight appeared widespread, both within and outside the dieback area. However, while the levels of infestation of the Asian gall wasp were similar within and outside the dieback area, the incidence of chestnut blight was significantly higher, in association with average levels of crown transparency exceeding 50\%, in the dieback area compared with the surrounding stands. Interestingly, it was recently shown that $C$. parasitica may infect abandoned galls of the Asian gall wasp (Meyer et al. 2015), thereby providing a clue supporting the hypothesis that chestnut blight could be the prevailing factor triggering the dieback. In addition, hail-induced wounds on small branches and shoots were observed with $100 \%$ incidence only in the dieback area suggesting either that the dieback was associated with the injuries caused by the hailstorms themselves, or that those injuries may have facilitated infections of the chestnut blight pathogen. It is worth noting that the patchy distribution and the extension of the dieback area, clearly visible from satellite imagery,

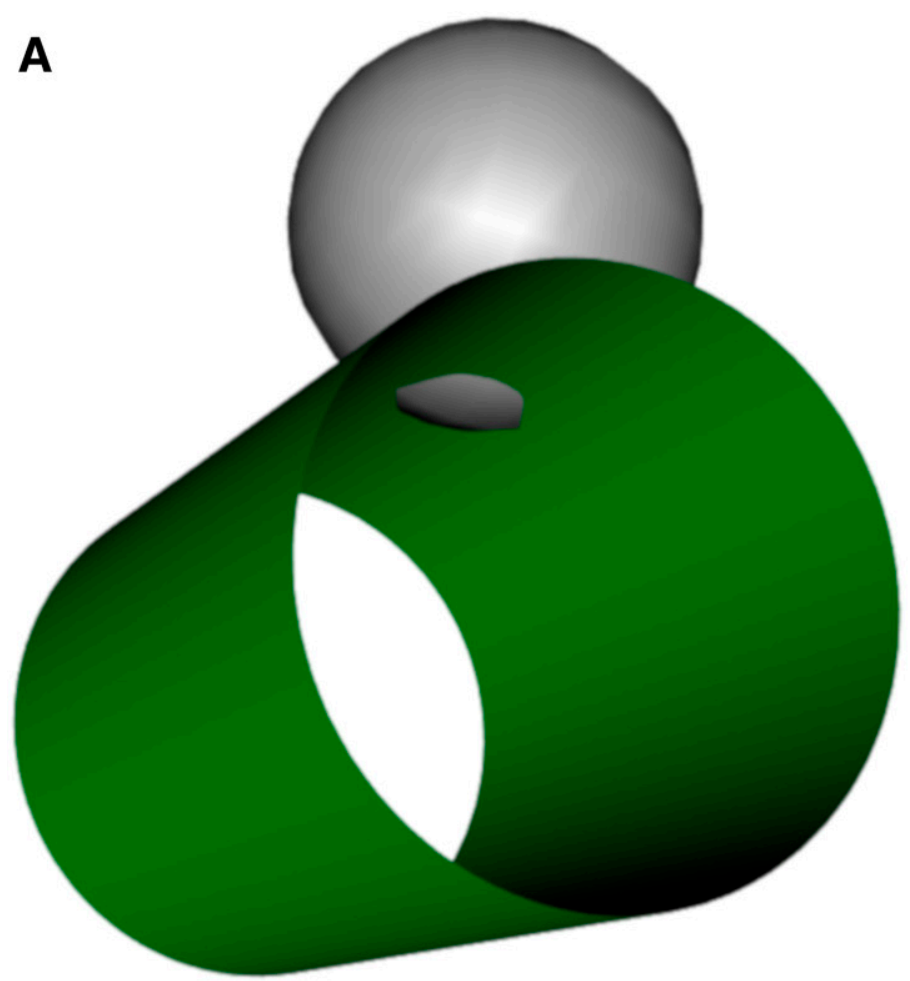

B

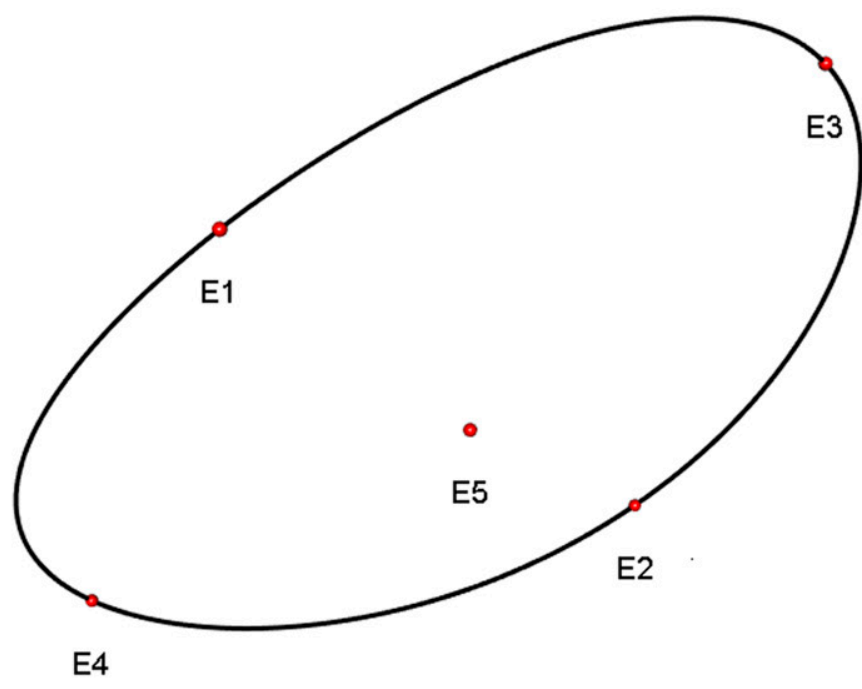

Fig. 4. Three-dimensional modeling of the shape of hail wounds on shoots based on the geometrical approximation of hail wound model. A, Impact of a hailstone (sphere) on the shoot surface (cylinder) with the related indentation associated with the hail injury. B, The hail wound perimeter where points mark the hail wound width (distance from $E_{1}$ to $E_{2}$ ), length (distance from $E_{3}$ to $E_{4}$ ), and the point of maximum depth reached by the wound $\left(E_{5}\right)$. 
is fully consistent with the expected outcomes of hailstorm events striking a hilly region located within the complex orographic conditions of North West of Italy (Baldi et al. 2014; Punge and Kunz 2016). On the contrary, the above spatial distribution of the decline is hardly compatible with the dynamics of the infestation and spread of D. kuriphilus (Lione et al. 2016; Paparella et al. 2016). The major role played by hailstorms in the dieback is supported by the reconstruction of the hailstorm events. Data about hailstorms at the local, regional, national, and European scale are notoriously difficult to obtain because of the lack of appropriate observation systems, and hence they are often and inevitably gathered based on reports from local people (Baldi et al. 2014; Mohr et al. 2015; Punge and Kunz 2016). These reports can be collected through interviews, by screening newspapers, or by querying databases from official institutions or datasets built thanks to the contribution of citizens and volunteers (Associazione ONLUS MeteoNetwork 2019; Baldi et al. 2014; Dotzek et al. 2009; Punge and Kunz 2016). Consulting as many relevant sources as possible is the key to gather reliable information from such citizen science-based approaches as we attempted to do in this study. In fact, as an example, the simple consultation of databases hinging on reports would not have been sufficient to detect the events we reconstructed from newspapers and interviews, simply because such events were not uploaded in the database systems, or because the system is still not adequate to distinguish hailstorms from other precipitations. In addition, as remarked by Dotzek et al. (2009), the frequency of reports feeding databases does not only depend on the frequency of events themselves, but also on the likelihood that events are reported by citizens and volunteers, thus highlighting once more the need of integrating the available multisource information. In this regard, the mosaic of information we gathered pointed out that at least four severe hailstorms had occurred in the dieback area. Remarkably, such hailstorms occurred during a timeframe consistent with the lifetime of the branches and shoots sampled in this study and with the onset of the blight symptoms observed. It is worth noting that event-based and nonsystematic reports (Punge and Kunz 2016) might be biased in reconstructing only major hailstorm events and omitting the others. However, this potential bias is unlikely to affect our results, since the 12,228 hail wounds we analyzed were created by all the hailstorms that occurred in the area, and not only by those hailstorms that our reconstruction could confirm. In fact, the ECDFs of the length and width measured for each of the above wounds display the presence of any wound size. While all wound sizes are represented, the sample is unbalanced toward wound perimeters under $100 \mathrm{~mm}$. This unbalance might have influenced the performance of the binary logistic regression modeling the risk of infection. However, this potential source of error is unlikely to affect significantly the reliability of our results, as confirmed by the analyses assessing the model performances and accounting for model uncertainty as well as for sample size adequacy (Grueber et al. 2011; Heiberger and Holland 2015; Hosmer and Lemeshow 1989; Peduzzi et al. 1996; Robin et al. 2011; Wagenmakers and Farrell 2004). In addition, the GAHW risk model we proposed (see below) accounts consistently not only for large-size hailstones related to the most severe hailstorms (Dessens et al. 2007), but also for all the others, including small-size hailstones. The empirical observation that the frequency and intensity of hailstorms have recently increased across the study area is confirmed by the available climatologies, pointing out that North West of Italy is at high risk of severe hail strikes, particularly in hill and mountainous areas (Baldi et al. 2014; Punge and Kunz 2016). Although we cannot exclude a direct role of hailstorms on the onset of the dieback, based on our isolation attempts we did find evidence that hail-induced wounds served as infection courts for $C$. parasitica. In addition, the incidence of chestnut blight was significantly higher in the dieback area compared with the surrounding stands further supporting the hypothesis that infections leading to dieback may have been driven by hailstorms. Hence, by attempting to classify the role of the different factors in the framework of the forest decline concepts (Manion 1981), we propose hailstorms as an inciting factor and the chestnut blight as a contributing factor of chestnut decline. In fact, as we showed in this study, hailstorms foster the infection of the chestnut blight pathogen and, possibly, behave as relevant stressors for the tree. It should be noted that some of the hailstorms putatively associated with the observed dieback occurred during the spring or in association with rainfalls in the fall providing a clue to explain massive infections. In fact, masses of infectious $C$. parasitica pycnospores are generally present in those periods of the year or in association with precipitations (Guérin et al. 1999; Robin and Heiniger 2001). In addition to wounds on small branches and shoots, hailstorms caused holes and ripping on leaves which, in turn, predictably affected the process of evapotranspiration, which is particularly active in the spring and summer. Such a phenomenon may have had effects similar to those of drought conditions, which have also been previously suggested to enhance the occurrence of C. parasitica infections (Prospero and Rigling 2013). Finally, we cannot exclude that the infestation of the Asian gall wasp, as well as other factors, including climate change and the age of trees, may have played the role of predisposing factors. In fact, the severity of the dieback may have been different in the absence of the infestation. However, our data does not allow testing of this hypothesis.

Data obtained from laboratory analyses allowed to point to a clear role played by the size of hail wounds rather than by their abundance as a factor triggering infections. It is worth noting that, despite the operational constraints resulting in a slightly unbalanced sample of symptomatic and asymptomatic branches and shoots, the conditional inference tree models we used are notoriously robust and reliable since they are based on algorithms hinging on unbiased recursive partitioning and conditional inference (Hothorn and Zeileis 2015; Hothorn et al. 2006). Indeed, infected shoots displayed a lower average number of hail wounds than uninfected shoots, yet the hail wounds associated with blight were significantly larger in size and more stretched in shape. This result is consistent with the infection dynamics and the epidemiology of $C$. parasitica, which is acknowledged as a pathogen whose infections are
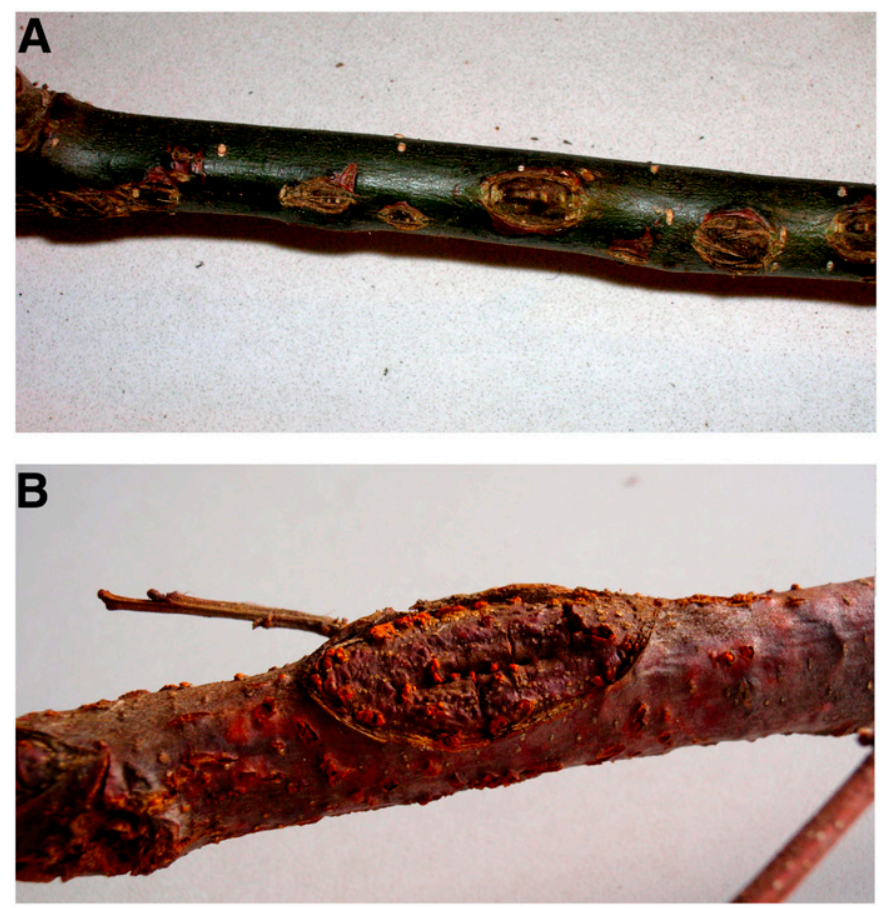

Fig. 5. Examples of hail-induced wounds detected on chestnut shoots sampled for this study. A, Hail-induced wounds not associated with Cryphonectria parasitica infection. B, Hail-induced wounds associated with symptoms of blight; orange fruiting bodies of $C$. parasitica emerge from the bark. 
prompted by the presence of wounds at the stem, branch and shoot levels (Prospero and Rigling 2013). Not surprisingly, the potential role of hailstorms in enhancing the occurrence of $C$. parasitica infections was previously hypothesized (EFSA PLH Panel (EFSA Panel on Plant Health) 2014; Turchetti et al. 2010). Nonetheless, this study reports the first experimentally based evidence providing quantitative information about the association between hail wounds, the infection process and the development of chestnut blight. Since infections by $C$. parasitica occur mainly through inoculum passively dispersed by air or water and deposited on the surface of injuries exposing the cambial tissue (Prospero and Rigling 2013), the infection can be deemed as a stochastic process (Lione and Gonthier 2016 and references within). Different stochastic models have been proposed so far to describe how spores and other particles endowed with comparable physical properties can spread and land, including random walks (Bicout and Sache 2003; Stockmarr 2002), the Ornstein-Uhlenbeck process (Dobrow 2016), the Lagrangian stochastic particle dispersion model (Kuparinen et al. 2007), and the homogeneous Poisson process (Illian et al. 2008). Since the probability that a spore will land on a specific surface depends on the surface dimension (Stockmarr 2002), an increased probability of spore deposition on the injury produced by hail might be reasonably expected with increasing dimensions of the wound surface. However, extensive Monte Carlo simulations studies (see for example Carsey and Harden 2014; Dobrow 2016; Lione and Gonthier 2016) based on the stochastic models listed above should be conducted to support this hypothesis.

Although all predictors related to the size of the hail wounds (length, width, perimeter, and surface) were significantly associated with the probability of infection by $C$. parasitica, the perimeter was the most adequate for risk assessment. This result may be interpretable by considering that $C$. parasitica is a fungal pathogen infecting mainly the thin cambium layer under the bark, rather than the inner plant tissues. Hence, once the wound has been created by the impact of a hailstone, the cambial tissue available for infection is likely to be located toward the perimeter of the injuries, rather than on the central portion. Nonetheless, no lines of evidence are currently available to support this hypothesis.

Based on the logistic models proposed in this study, it is now possible appraising the risk of infection by $C$. parasitica through the measurement of the length and width of the hail wound. While this approach can be useful for in-field monitoring, risk assessment, and modeling, it does not suffice for the appraisal of which hailstorm intensity could boost the onset or resurgence of the chestnut blight. For this purpose, we attempted to appraise the association between hailstones size, hail wound perimeter and the risk of infection through the newly designed geometrical-based model GAHW. The GAHW model relies on the assumption that the damage caused by hail strikes on chestnut is directly correlated with the size of hailstones. Although other variables may influence the magnitude of the damage caused by hailstorms, such as hail density, wind speed and direction (Changnon et al. 2009), hail size is by far the main indicator of hailstorm-related damages (Punge et al. 2014). Not surprisingly, many studies were focused on the importance of hailstone size (Baldi et al. 2014). For instance, agricultural losses are expected to occur when the hailstone size increases over the threshold of $5 \mathrm{~mm}$ (Punge and Kunz 2016). Damages to wheat, corn and soybean crops are more likely if the diameter of hailstone is over the cut-off value of $6.35 \mathrm{~mm}$ (Changnon 1971). In addition, inventories referring to economic losses of the major hailstorm events observed in Europe from 1788 to 2014 relate to the diameter of the hailstones (Punge and Kunz 2016). For the above reasons, hailstone size along with its kinetic energy stand among the main indicators of hailstorm severity included in damage models (Punge et al. 2014; Vinet 2001; Walsh et al. 2016), as well as in hail intensity/damage scales such as ANELFA (Dessens et al. 2007). It is worth noting that damage is related to the logarithm of the hail kinetic energy, which is proportional to the 4th power of the hailstone diameter (Baldi et al. 2014). Hence, the assumption that hailstones size and hail wound perimeter are correlated seems to be supported by the lines of evidence listed above, while the relation linking the perimeter and the risk of infection by $C$. parasitica was unraveled by our binary logistic regression model. The GAHW model provided a three-dimensional rendering of the hail wound that was consistent both with the observations of the hail injuries observed on the sampled shoots and with the information reported in the literature (Costello 2014; Schubert 1991). One of the main constraints of this model is the geometrical rather than the physical approach. Nonetheless, the state of the art about the static and dynamic physical properties of young branches and shoots of chestnut is unlikely to allow a reliable parametrization of a physicalbased model. In fact, even under the simplification introduced in GAHW, the minimal information required to calculate the

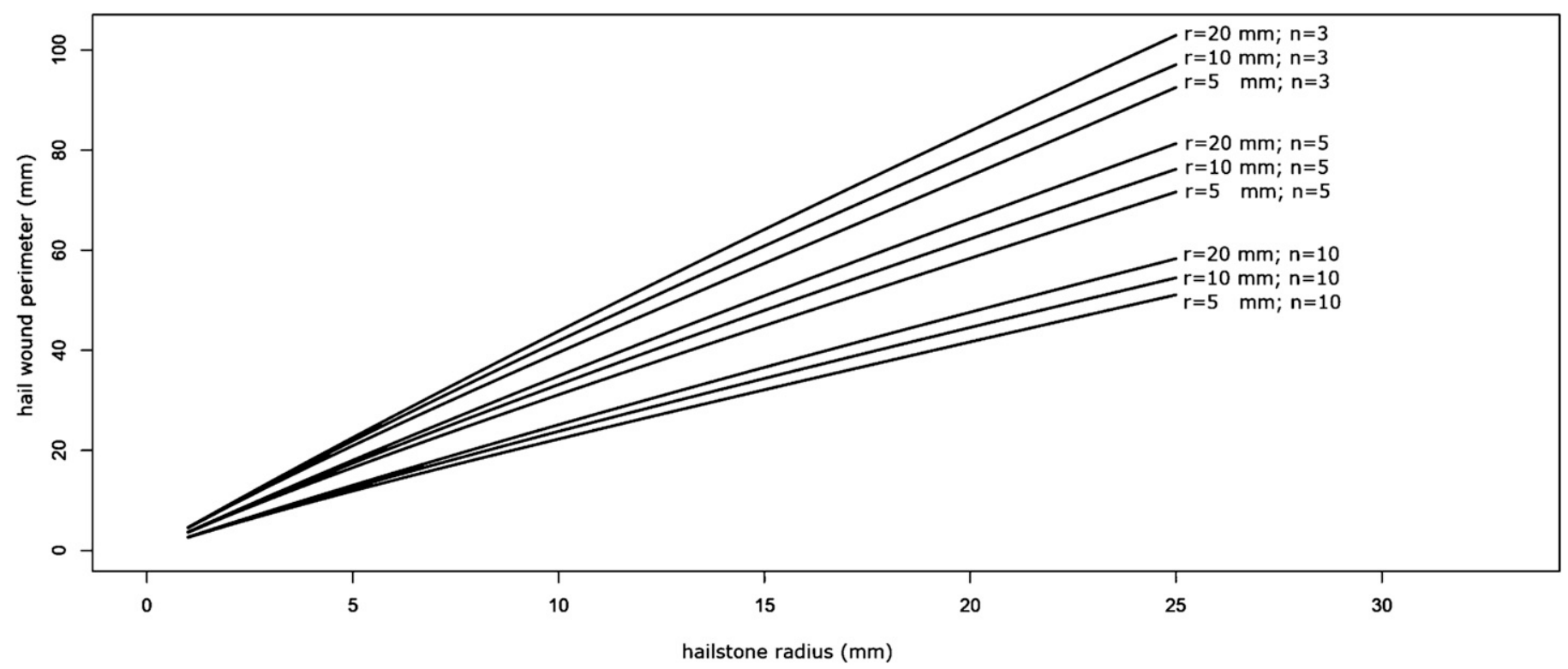

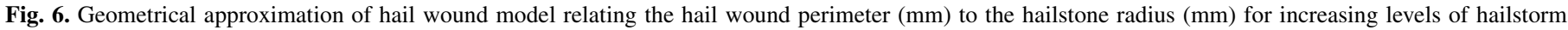
severity (from $n=10$ to $n=3$ ) and radius of the shoot (from $r=5 \mathrm{~mm}$ to $r=20 \mathrm{~mm}$ ). Values of $n$ are inversely proportional to hailstorm severity. 
equations proposed by Puttock and Thwaite (1969) and Sun et al. (2015) is not available, hampering the precise assessment of the forces involved and the depth of the hailstone penetration during the impact. The same issue does not allow a reliable modeling of nonorthogonal impacts. Nonetheless, there is a general agreement about the direct proportionality linking hailstone radius, velocity, impact force, and depth of penetration in the stricken target (Baldi et al. 2014; Field et al. 2010; Punge and Kunz 2016; Puttock and Thwaite 1969; Sun et al. 2015). Hence, the choice of expressing the hailstorm severity through the GAHW parameter (n), relating the indentation of the hail wound to a fraction of the hailstone radius, holds reasonable. It is worth noting that this choice allows to account for other factors that, in addition to hailstone size, could influence the severity of the impact, with emphasis on wind. Indeed, windy hailstorms may increase the hailstones kinetic energy and consequently produce damages more detrimental than those resulting from a hailstorm with the same hailstones size, but in the absence of wind (Baldi et al. 2014; Towery et al. 1976). Consistently, the GAHW model shows that a reduction in the value of $n$ accounting for an increased intensity of the hailstone impact generates larger hail wounds for any given hailstone size. The estimates of the wound depth through $n$ values set from 3 to 10 seem consistent with the dimensions of hailstones reported by local people in the study area, with the average dimensions of hailstones in Italy (Baldi et al. 2014) and with the depth of the hail wounds observed in the sampled branches and shoots of chestnut. Interestingly, while the field data showed a range of hail wound perimeters up to approximately $300 \mathrm{~mm}$, GAHW model produced as output a maximum of approximately $100 \mathrm{~mm}$. Since hailstones with a radius over $20 \mathrm{~mm}$ occur only in $3.5 \%$ of cases (Punge and Kunz 2016) and considering that the difference between 300 and $100 \mathrm{~mm}$ is too large to only depend upon potential errors in input parameters, the most likely explanation relies in the type of impact of hailstone on shoot. In fact, GAHW is based on the assumption of orthogonality between the hailstone trajectory and the growth axis of the shoot, a condition that might not be met in the field especially during windy and turbulent hailstorms. Hence, it seems reasonable inferring that perimeters over $100 \mathrm{~mm}$ are caused by nonorthogonal impacts. The corresponding hail wounds are consequently expected to be more severe based on the increased kinetic energy of the hailstones (Baldi et al. 2014) and potentially more stretched. This hypothesis is confirmed by the fact that hail wounds with a higher eccentricity were associated with a significantly higher risk of infection by $C$. parasitica. Nonetheless, the bark thickness could also play a role by potentially affecting the shape and dimensions of hail wounds, although this factor would require a different experimental design to be accounted for in a risk model. GAHW is the first model that could be used to estimate the risk of infection by $C$. parasitica based on hailstone size. However, further studies of contact physics, wood technology, and hailstorm meteorology are needed to improve the risk assessment of chestnut blight insurgence.

On the whole, $6.5 \%$ of $C$. parasitica isolates analyzed in this study through the newly developed TaqMan-based real-time PCR assay were infected by CHV-1. Unfortunately, no specific studies have been carried out to investigate the prevalence of hypovirulence at the population level in the North West of Italy, which may have been helpful for comparative purposes. In a recent study conducted in different chestnut stands in Europe, the percentage of isolates bearing CHV-1 ranged from 6.9 to $61.5 \%$, depending on site (Ježić et al. 2019). Thus, hypovirulence in our study sites seems to be low in comparison with the range reported by Ježić et al. (2019), which may provide a further clue to interpret the severity of the dieback. Whether the low prevalence of hypovirulence in our samples may be a trait linked either to the pathogen populations in the area, including the diversity of their vegetative compatibility groups (VCGs), or to the selection for virulent strains of the pathogen during infection through hail wounds remains an open question deserving further studies. Nevertheless, the detection of CHV-1 in our fungal samples clearly indicates that infections incited by hail wounds may involve both virus-free (virulent) and virus-infected (hypovirulent) strains of the pathogen.

Locally distributed diebacks of chestnut orchards and coppices were also reported elsewhere in Piedmont, North West of Italy. Although no detailed investigations were conducted to unravel the causes of those diebacks, field surveys confirmed that those additional dieback areas had been challenged by both chestnut blight and hailstorms, supporting a role of these two factors in the occurrence of diebacks. It is worth noting that Piedmont owns some of the highest records of hailstorm events in Italy (Baldi et al. 2014; Punge and Kunz 2016). Although forecasts are challenging in this sense, it seems likely that an increased frequency and severity of hailstorm events might be expected for the near future (Baldi et al. 2014; Punge and Kunz 2016) as a result of anthropogenic climate change leading to the alteration of large-scale circulation and weather patterns (Brimelow et al. 2017; Kunz et al. 2009).

In conclusion, in this study we provided a new and quantitativebased piece of information on the effects of hailstorms on the epidemiology of $C$. parasitica while exploring the factors involved in a sudden dieback of chestnut trees in Northern Italy. Since the frequency and possibly the intensity of hailstorms are on the rise and chestnut blight is highly prevalent in most of the natural range of chestnut, diebacks observed in the North West of Italy may become more and more common.

\section{ACKNOWLEDGMENTS}

We thank the Editor and the anonymous Reviewers for the insightful suggestions.

\section{LITERATURE CITED}

Adler, D., and Murdoch, D. 2019. rgl: 3D Visualization Using OpenGL. R package version 0.100.26. https://cran.r-project.org/web/packages/rgl/index.html

ARPA-Piemonte. 2019. Banca Dati Meteorologica-Stazione termoigro-pluviobaroane mometrica con sensori nivologici-codice 107. https://www.arpa.piemonte.it/ rischinaturali/accesso-ai-dati/annali_meteoidrologici/annali-meteo-idro/bancadati-meteorologica.html

ARPA-Piemonte. 2020. Banca Dati Meteorologica e Idrologica. ARPA. http:// www.arpa.piemonte.it

Associazione ONLUS MeteoNetwork. 2019. Storm Report Meteonetwork Dataset. https://www.meteonetwork.it/tt/stormreport/

Avtzis, D. N., Melika, G., Matošević, D., and Coyle, D. R. 2019. The Asian chestnut gall wasp Dryocosmus kuriphilus: A global invader and a successful case of classical biological control. J. Pest Sci. 92:107-115.

Baldi, M., Ciardini, V., Dalu, J. D., De Filippis, T., Maracchi, G., and Dalu, G. 2014. Hail occurrence in Italy: Towards a national database and climatology. Atmos. Res. 138:268-277.

Barton, K. 2019. MuMIn: Multi-Model Inference. R package version 1.43.6. https://cran.r-project.org/web/packages/MuMIn/index.html

Bicout, D. J., and Sache, I. 2003. Dispersal of spores following a persistent random walk. Phys. Rev. E 67:031913.

Bissegger, M., and Sieger, T. N. 1994. Assemblages of endophytic fungi in coppice shoots of Castanea sativa. Mycologia 86:648-655.

Blaker, H. 2000. Confidence curves and improved exact confidence intervals for discrete distributions. Can. J. Stat. 28:783-798.

Bobev, S., and Deckers, T. 1999. Field susceptibility to fire blight of pome fruits in Bulgaria. Acta Hortic. 489:221-224.

Bonifacio, A., and Turchetti, T. 1973. Differenze morfologiche e fisiologiche in isolati di Endothia parasitica (Murr.) And. Ann. Acc. Ital. di Sci. For. 22: 111-131.

Bounous, G., and Torello Marinoni, D. 2005. Chestnut: Botany, horticulture, and utilization. Hortic. Rev. (Am. Soc. Hortic. Sci.) 31:291-347.

Brimelow, J. C., Burrows, W. R., and Hanesiak, J. M. 2017. The changing hail threat over North America in response to anthropogenic climate change. Nat. Clim. Chang. 7:516-522.

Cariddi, P. 2011. Maltempo in Piemonte, fiumi in piena. Ed è ancora allerta meteo almeno per altre 48 ore! METEOWEB 06/11/2011. http:// www.meteoweb.eu/2011/11/maltempo-in-piemonte-fiumi-in-piena-ede-ancora-allerta-meteo-almeno-per-altre-48-ore-foto-e-video/96366/

Carpenter, J., and Bithell, J. 2000. Bootstrap confidence intervals: When, which, what? A practical guide for medical statisticians. Stat. Med. 19: 1141-1164. 
Carsey, T. M., and Harden, J. J. 2014. Monte Carlo Simulation and Resampling Methods for Social Science. SAGE Publications, Thousand Oaks, CA.

Chandelier, A., Massot, M., Fabreguettes, O., Gischer, F., Teng, F., and Robin, C. 2019. Early detection of Cryphonectria parasitica by real-time PCR. Eur. J. Plant Pathol. 153:29-46.

Changnon, S. A. 1971. Note on hailstone size distributions. J. Appl. Meteorol. 10:168-170.

Changnon, S. A., Changnon, D., and Hilberg, S. 2009. Hailstorms Across the Nation. An Atlas about Hail and its Damages. Illinois State Water Survey, Champaign, IL.

Conedera, M., Krebs, P., Tinner, W., Pradella, M., and Torriani, D. 2004a. The cultivation of Castanea sativa (Mill.) in Europe, from its origin to its diffusion on a continental scale. Veg. Hist. Archaeobot. 13:161-179.

Conedera, M., Manetti, M. C., Giudici, F., and Amorini, E. 2004b. Distribution and economic potential of the sweet chestnut (Castanea sativa Mill.) in Europe. Ecol. Mediterr. 30:179-193.

Costello, L. R. 2014. Abiotic Disorders of Landscape Plants: A Diagnostic Guide, Vol. 3420. University of California Agriculture and Natural Resources.

Crawley, M. J. 2013. The R Book. 2nd ed. John Wiley \& Sons, Chichester, U.K.

Dessens, J., Berthet, C., and Sanchez, J. L. 2007. A point hailfall classification based on hailpad measurements: The ANELFA scale. Atmos. Res. 83: 132-139.

DiCiccio, T. J., and Efron, B. 1996. Bootstrap confidence intervals. Stat. Sci. 11:189-228.

Dobrow, R. P. 2016. Introduction to Stochastic Processes with R. John Wiley \& Sons, Chichester, U.K.

Dotzek, N., Groenemeijer, P., Feuerstein, B., and Holzer, A. M. 2009. Overview of ESSL's severe convective storms research using the European Severe Weather Database ESWD. Atmos. Res. 93:575-586.

Durrant, D., Eichhorn, J., Ferretti, M., Roskams, P., and Szepesi, A. 2006. Manual on methods and criteria for harmonized sampling, assessment, monitoring and analysis of the effects of air pollution on forests, Part II, Visual Assessment of Crown Condition. United Nations Economic Commission for Europe Convention on long-range transboundary air pollution, United Nations.

Efron, B., and Tibshirani, R. J. 1994. An introduction to the bootstrap. R package version 2019.6. https://cran.r-project.org/web/packages/bootstrap/ index.html

EFSA PLH Panel (EFSA Panel on Plant Health). 2014. Scientific opinion on the pest categorisation of Cryphonectria parasitica (Murrill). Barr. EFSA J. 12:3859.

EPPO. 2005. PM 7/45(1) Cryphonectria parasitica. Bull. OEPP/EPPO Bull. 35:295-298.

ESRI. 2019. ESRI shaded relief, accessed on 17/12/2019 through QGIS QuickMapServices plugin version 0.19.11.1. https://plugins.qgis.org/ plugins/quick_map_services/

Field, P. R., Hand, W., Cappelluti, G., McMillan, A., Foreman, A., Stubbs, D., and Willows, M. 2010. Hail threat standardization, FINAL Report for EASA. 2008. OP. 25 .

Gehring, E., Kast, C., Kilchenmann, V., Bieri, K., Gehrig, R., Pezzatti, G. B., and Conedera, M. 2018. Impact of the Asian chestnut gall wasp, Dryocosmus kuriphilus (Hymenoptera, Cynipidae), on the chestnut component of honey in the Southern Swiss Alps. J. Econ. Entomol. 111: 43-52.

Giordano, L., and Gonthier, P. 2011. An outbreak of Cyclaneusma minus needle cast on Swiss mountain pine (Pinus uncinata) in Italy. J. Plant Pathol. 93(Suppl. 4):S4.74.

Giordano, L., Gonthier, P., Varese, G. C., Miserere, L., and Nicolotti, G. 2009. Mycobiota inhabiting sapwood of healthy and declining Scots pine (Pinus sylvestris L.) trees in the Alps. Fungal Divers. 38:69-83.

Gonthier, P., Giordano, L., and Nicolotti, G. 2010. Further observations on sudden diebacks of Scots pine in the European Alps. For. Chron. 86: 110-117.

Gonthier, P., and Robin, C. 2020. Diseases. Pages 297-315 in: The Chestnut Handbook: Crop \& Forest Management. G. L. Beccaro, A. Alma, G. Bounous, and J. C. Laranjo, eds. Taylor and Francis Group, Oxfordshire, U.K

Google. 2019. Google Satellite, Map data 2015 Google, accessed on 17/12/ 2019 through QGIS QuickMapServices plugin version 0.19.11.1.

Grente, J., and Sauret, S. 1969. L'hypovirulence exclusive, phénomène original en pathologie végétale. C. R. Hebd. Séance Acad. Sci. 268: 2347-2350.

Grueber, C. E., Nakagawa, S., Laws, R. J., and Jamieson, I. G. 2011. Multimodel inference in ecology and evolution: challenges and solutions. J. Evol. Biol. 24:699-711.

Guérin, L., Bastien, S., and Chauvin, B. 1999. The production and dispersal of ascospores of Cryphonectria parasitica in an orchard in south-western France. Acta Hortic. 494:473-480.
Heiberger, R. M., and Holland, B. 2015. Logistic Regression. Pages 593-629 in: Statistical Analysis and Data Display. R. M. Heiberger and B. Holland, eds. Springer Texts in Statistics, Springer, New York.

Hosmer, D. W., and Lemeshow, S. 1989. Applied Logistic Regression. Johns Wiley \& Sons, New York.

Hothorn, T., Hornik, K., and Zeileis, A. 2006. Unbiased recursive partitioning: A conditional inference framework. J. Comput. Graph. Stat. 15:651-674.

Hothorn, T., and Zeileis, A. 2015. partykit: A modular toolkit for recursive partytioning in R. J. Mach. Learn. Res. 16:3905-3909. http://jmlr.org/ papers/v16/hothorn15a.html

Illian, J., Penttinen, A., Stoyan, H., and Stoyan, D. 2008. Statistical Analysis and Modelling of Spatial Point Patterns. John Wiley \& Sons, Chichester, U.K.

IPLA-Regione Piemonte. 2007. Carta dei Suoli del Piemonte (1: 250.000). Ed. Selca, Firenze. Accessed through the Regione Piemonte official web service. https://www.regione.piemonte.it/web/temi/agricoltura

Ježić, M., Kolp, M., Prospero, S., Sotirovski, K., Double, M., Rigling, D., Risteski, M., Karin-Kujundžić, V., Idžojtić, M., Poljak, I., and ĆurkovićPerica, M. 2019. Diversity of Cryphonectria parasitica in callused chestnut blight cankers on European and American chestnut. For. Pathol. 49: e12566.

Jung, T., Blaschke, H., and Obwald, W. 2000. Involvement of soilborne Phytophthora species in Central European oak decline and the effect of site factors on the disease. Plant Pathol. 49:706-718.

Kunz, M., Sander, J., and Kottmeier, C. 2009. Recent trends of thunderstorm and hailstorm frequency and their relation to atmospheric characteristics in southwest Germany. Int. J. Climatol. 29:2283-2297.

Kuparinen, A., Markkanen, T., Riikonen, H., and Vesala, T. 2007. Modeling air-mediated dispersal of spores, pollen and seeds in forested areas. Ecol. Modell. 208:177-188.

Lanthier, M. 2011. Summer outbreaks of fire blight in tree nurseries in South Alberta, Canada. Acta Hortic. 896:293-300.

Lione, G., Danti, R., Fernandez-Conradi, P., Ferreira-Cardoso, J. V., Lefort, F., Marques, G., Meyer, J. B., Prospero, S., Radócz, L., Robin, C., Turchetti, T., Vettraino, A. M., and Gonthier, P. 2019. The emerging pathogen of chestnut Gnomoniopsis castaneae: The challenge posed by a versatile fungus. Eur. J. Plant Pathol. 153:671-685.

Lione, G., Ebone, A., Petrella, F., Terzuolo, P., Nicolotti, G., and Gonthier, P. 2012. Decline of Quercus robur forests in northwestern Italy: Current situation and tentative aetiology. Integrated Protection in Oak Forests. IOBC WPRS Bull. 76:67-70.

Lione, G., Giordano, L., Ferracini, C., Alma, A., and Gonthier, P. 2016. Testing ecological interactions between Gnomoniopsis castaneae and Dryocosmus kuriphilus. Acta Oecol. 77:10-17.

Lione, G., and Gonthier, P. 2016. A permutation-randomization approach to test the spatial distribution of plant diseases. Phytopathology 106: 19-28.

Manion, P. D. 1981. Tree Disease Concepts. Prentice-Hall, New York.

Meyer, J. B., Gallien, L., and Prospero, S. 2015. Interaction between two invasive organisms on the European chestnut: Does the chestnut blight fungus benefit from the presence of the gall wasp? FEMS Microbiol. Ecol. 91:fiv122.

Milgroom, M. G., and Cortesi, P. 2004. Biological control of chestnut blight with hypovirulence: A critical analysis. Annu. Rev. Phytopathol. 42: 311-338.

Miller, B. A., and Schaetzl, R. J. 2015. Digital classification of hillslope position. Soil Sci. Soc. Am. J. 79:132-145.

Mohr, S., Kunz, M., and Geyer, B. 2015. Hail potential in Europe based on a regional climate model hindcast. Geophys. Res. Lett. 42:10904-10912.

Müller, E., and Stierlin, H. R. 1990. Sanasilva Tree Crown Photos with Percentages of Foliage Loss. Swiss Federal Institute for Forest, Snow, and Landscape Research, Birmensdorf, Switzerland.

Ôtake, A. 1980. Chestnut gall wasp, Dryocosmus kuriphilus Yasumatsu (Hymenoptera: Cynipidae): A preliminary study on trend of adult emergence and some other ecological aspects related to the final stage of its life cycle. Appl. Entomol. Zool. 15:96e105.

Paparella, F., Ferracini, C., Portaluri, A., Manzo, A., and Alma, A. 2016. Biological control of the chestnut gall wasp with T. sinensis: A mathematical model. Ecol. Modell. 338:17-36.

Pasche, S., Calmin, G., Auderset, G., Crovadore, J., Pelleteret, P., Mauch-Mani, B., Barja, F., Paul, B., Jermini, M., and Lefort, F. 2016. Gnomoniopsis smithogilvyi causes chestnut canker symptoms in Castanea sativa shoots in Switzerland. Fungal Genet. Biol. 87:9-21.

Peduzzi, P., Concato, J., Kemper, E., Holford, T. R., and Feinstein, A. R. 1996. A simulation study of the number of events per variable in logistic regression analysis. J. Clin. Epidemiol. 49:1373-1379.

Prieri, A. 2012. Grandinata record, gravi danni all'agricoltura, La Stampa. https://www.lastampa.it/cuneo/2012/06/19/news/grandinata-record-gravi-danniall-agricoltura-1.36471561 
Prospero, S., and Rigling, D. 2013. Chestnut blight. Pages 318-329 in: Infectious Forest Diseases. P. Gonthier and G. Nicolotti, eds. CAB International, Wallingford, U.K.

Punge, H. J., Bedka, K. M., Kunz, M., and Werner, A. 2014. A new physically based stochastic event catalog for hail in Europe. Nat. Hazards 73:1625-1645.

Punge, H. J., and Kunz, M. 2016. Hail observations and hailstorm characteristics in Europe: A review. Atmos. Res. 176:159-184.

Puttock, M. J., and Thwaite, E. G. 1969. Elastic compression of spheres and cylinders at point and line contact. Commonwealth Scientific and Industrial Research Organization, Melbourne, Australia.

QGIS Development Team. 2019. QGIS Geographic Information System. Open Source Geospatial Foundation Project. https://qgis.org

Quacchia, A., Moriya, S., Bosio, G., Scapin, I., and Alma, A. 2008. Rearing, release and settlement prospect in Italy of Torymus sinensis, the biological control agent of the chestnut gall wasp Dryocosmus kuriphilus. BioControl 53:829-839.

R Core Team. 2019. R: A language and environment for statistical computing. R Foundation for Statistical Computing, Vienna, Austria. https://www.Rproject.org/

Rigling, D., and Prospero, S. 2018. Cryphonectria parasitica, the causal agent of chestnut blight: Invasion history, population biology and disease control. Mol. Plant Pathol. 19:7-20.

Robin, C., and Heiniger, U. 2001. Chestnut blight in Europe: diversity of Cryphonectria parasitica, hypovirulence and biocontrol. For. Snow Landsc. Res. 76:361-367.

Robin, X., Turck, N., Hainard, A., Tiberti, N., Lisacek, F., Sanchez, J. C., and Müller, M. 2011. pROC: An open-source package for R and S+ to analyze and compare ROC curves. BMC Bioinformatics 12:77.

Ross, J., Sulev, M., and Saarelaid, P. 1998. Statistical treatment of the PAR variability and its application to willow coppice. Agric. For. Meteorol. 91:1-21.

Schubert, T. S. 1991. Hail Damage to Plants. Florida Department of Agriculture \& Consumer Services, Division of Plant Industry.

Smith, H. S., Coutinho, T. A., Wolfaardt, F. W., and Wingfield, M. J. 2002. Relative susceptibility of northern and southern provenances of Pinus greggii to infection by Sphaeropsis sapinea. For. Ecol. Manage. 166:331-336.

Stockmarr, A. 2002. The distribution of particles in the plane dispersed by a simple 3-dimensional diffusion process. J. Math. Biol. 45:461-469.
Sun, J., Lam, N., Zhang, L., Ruan, D., and Gad, E. 2015. Contact forces generated by hailstone impact. Int. J. Impact Eng. 84:145-158.

Towery, N. G., Morgan, G. M., Jr., and Changnon, S. A., Jr. 1976. Examples of the wind factor in crop-hail damage. J. Appl. Meteorol. 15:1116-1120.

Turchetti, T. 1978. Some observation on the "Hypovirulence" of chestnut blight in Italy. Pages 92-94 in: Proceedings of the American Chestnut Symposium. W. L. MacDonald, F. C. Cech, J. Luchok, and C. Smith, eds. WV University, Morgantown, USA.

Turchetti, T., Addario, E., and Maresi, G. 2010. Situation and evolution of sanitary status in chestnut stands. Acta Hortic. 866:385-392.

Van Den Besselaar, E. J., Klein Tank, A. M., Van Der Schrier, G., Abass, M. S., Baddour, O., Van Engelen, A. F., Freire, A., Hechler, P., Laksono, B. I., Iqbal, Jilderda, R., Foamouhoue, A. K., Kattenberg, A., Leander, R., Güingla, R. M., Mhanda, A. S., Nieto, J. J., Sunaryo, Suwondo, A., Swarinoto, Y. S., and Verver, G. 2015. International climate assessment \& dataset: Climate services across borders. Bull. Am. Meteorol. Soc. 96:16-21.

Villarino, M. B. 2006. A note on the accuracy of Ramanujan's approximative formula for the perimeter of an ellipse. JIPAM 7(1-21):1-10.

Vinet, F. 2001. Climatology of hail in France. Atmos. Res. 56:309-323.

Visentin, I., Gentile, S., Valentino, D., Gonthier, P., Tamietti, G., and Cardinale, F. 2012. Gnomoniopsis castanea sp. nov. (Gnomoniaceae, Diaporthales) as the causal agent of nut rot in sweet chestnut. J. Plant Pathol. 94:411-419.

Vogt, J., Fonti, P., Conedera, M., and Schröder, B. 2006. Temporal and spatial dynamic of stool uprooting in abandoned chestnut coppice forests. For. Ecol. Manage. 235:88-95.

Wagenmakers, E. J., and Farrell, S. 2004. AIC model selection using Akaike weights. Psychon. Bull. Rev. 11:192-196.

Walsh, K., White, C. J., McInnes, K., Holmes, J., Schuster, S., Richter, H., Evans, J. P., Di Luca, A., and Warren, R. A. 2016. Natural hazards in Australia: Storms, wind and hail. Clim. Change 139:55-67.

Zeileis, A., Leisch, F., Hornik, K., and Kleiber, C. 2002. strucchange: An R package for testing for structural change in linear regression models. J. Stat. Softw. 7:1-38.

Zwolinski, J. B., Swart, W. J., and Wingfield, M. J. 1995. Association of Sphaeropsis sapinea with insect infestation following hail damage of Pinus radiata. For. Ecol. Manage. 72:293-298. 